\title{
QUALIDADE DE VIDA EM PORTADORES DE DOENÇA ARTERIAL CORONÁRIA SUBMETIDOS A DIFERENTES TRATAMENTOS: COMPARAÇÃO ENTRE GÊNEROS
}

\author{
MARIA ELENITA CORRÊA DE SAMPAIO FAVARATO
}

Tese apresentada ao Departamento de Saúde Materno - Infantil da Faculdade de Saúde Pública da Universidade de São Paulo para obtenção do grau de Doutor em Saúde Pública.

ORIENTADOR: PROF. DR. JOSÉ MENDES ALDRIGHI 
"Se bastasse reparar o corpo do doente para que a ordem se restabelecesse e se começasse a vida, as dificuldades encontradas pelos médicos, no exercício de sua profissão, quase não seriam diferentes das encontradas pelos mecânicos “.

Danièle Brun 
Aos meus pais, por terem me iniciado nos caminhos da vida.

A Desiderio e Maria Helena, companheiros queridos, por toda importância e significado em minha vida. 


\section{AGRADECIMENTOS}

Ao Prof. Dr. José Mendes Aldrighi pela valiosa orientação e oportunidade de desenvolver este trabalho em uma parceria envolta por confiança e incentivo.

Ao Prof. Dr. Whady Armindo Hueb coordenador do projeto MASS II, pela grande confiança em nós depositada.

À Prof Dra. Bellkiss Wilma Romano, diretora do Serviço de Psicologia do InCor, pelo incentivo durante nossa convivência no percurso profissional.

Às bibliotecárias da Faculdade de Saúde Pública pela atenciosa revisão das referências bibliográficas. 


\section{ÍNDICE}

1 INTRODUÇÃO

1.1 DAC: Fatores de risco e formas de tratamento 3

1.2 DAC: Aspectos emocionais 4

1.3 DAC: Diferença entre gêneros 6

1.4 DAC e climatério 99

1.5 Avaliação de qualidade de vida em portadores de DAC 13

2 OBJETIVOS 17

3 MÉTODO $\quad 18$

$\begin{array}{ll}3.1 \text { Casuística } & 18\end{array}$

3.2 Instrumentos $\quad 19$

3.2.1 Questionário genérico de avaliação de qualidade de vida (SF-36) 19

3.2.2 Questionário de investigação do perfil demográfico $\quad 21$

3.3 Procedimentos estatísticos $\quad 21$

4 RESULTADOS $\quad 22$

5 DISCUSSÃO $\quad 45$

6 CONCLUSÕES $\quad 55$

7 REFERÊNCIAS $\quad 56$

ANEXOS

Anexo 1 - Termo de consentimento livre e esclarecido

Anexo 2 - Questionário genérico de avaliação de qualidade de vida (SF-36)

Anexo 3 - Questionário de investigação do perfil demográfico 


\section{INTRODUÇÃO}

Diversos aspectos motivam o estudo da qualidade de vida na área de saúde. Durante muito tempo o impacto das doenças em termos de saúde pública foi avaliado pelos índices de mortalidade. Mais recentemente, a Organização Mundial de Saúde, em conjunto com o Banco Mundial e a Escola de Saúde Pública da Universidade de Harvard propuseram que o ônus causado pelas doenças fosse avaliado em termos de anos de vida perdidos por morte prematura ou vividos com incapacidade importante (MURRAY et al, 1996).

Além disso, a necessidade de avaliar a efetividade das intervenções médicas justifica-se pela proliferação de diferentes formas de tratamento das doenças e pelo custo elevado das intervenções. As especialidades médicas que lidam com doenças agudas podem avaliar o efeito do tratamento, relacionando-o a cura. Porém, as especialidades que atuam com doenças crônicas e/ou recorrentes estão procurando outras perspectivas de avaliação dos resultados, que não focalizem apenas a dimensão médica de redução da morbi-mortalidade. Outras perspectivas devem ser consideradas como estado clínico, impacto sobre a família, custo, alocação de recursos limitados e qualidade de vida (FLECK, 2000). Um dos maiores desenvolvimentos no campo da saúde tem sido o reconhecimento da importância do ponto de vista do paciente em relação à sua doença, bem como a monitorização da qualidade das medidas terapêuticas empregadas. A literatura médica tem afirmado que a melhor medida de qualidade de um tratamento é o resultado obtido quanto aos objetivos fundamentais de 
prolongar a vida, aliviar a dor, restaurar a função e prevenir a incapacidade (BOWLING, 1995).

Dentro desse contexto emerge o conceito de qualidade de vida que valoriza a perspectiva do paciente frente a várias dimensões de sua vida e não só em relação à intensidade de sintomas de sua doença.

A Organização Mundial de Saúde por meio de um grupo de especialistas definiu qualidade de vida como "a percepção do indivíduo da sua posição na vida dentro do contexto cultural e de valores em que ele vive, bem como em relação a seus objetivos, expectativas, padrões e preocupações" (THE WHOQOL GROUP,1998). Nessa definição está implícito que qualidade de vida envolve um conceito subjetivo, multidimensional e inclui elementos de avaliação tanto positivos como negativos. Portanto, qualidade de vida vai além da presença ou ausência de sintomas. Os sentimentos de bem estar, fatores econômicos e as expectativas de vida exercem forte influência.

A saúde não é mais medida pela presença ou não de doença, e sim pelo grau de preservação da capacidade funcional. O resultado de um tratamento bem sucedido deve manter a autonomia do indivíduo, bem como mante-lo integrado socialmente e capaz de realizar suas atividades da vida diária. Capacidade funcional surge, portanto, como um novo paradigma de saúde (RAMOS, 2003). 


\subsection{DOENÇA ARTERIAL CORONÁRIA: FATORES DE RISCO E FORMAS DE TRATAMENTO}

Nos portadores de doença arterial coronária (DAC) é importante considerar o caráter multifatorial envolvido, isto é, a DAC depende, entre outros da herança genética, da maneira de viver e das condições ambientais. Os parâmetros que guardam alguma relação com a DAC são chamados de "fatores de risco" e, entre eles incluem-se a idade, sexo, hipercolesterolemia, tabagismo, hipertensão arterial, obesidade, diabetes, hereditariedade, vida sedentária e estresse (DAWBER, 1980 ).

A manifestação da DAC é variada, ou seja, evolui desde a completa ausência de sintomas, angina incapacitante, infarto do miocárdio até morte súbita.

As principais possibilidades terapêuticas para a DAC podem ser tratamento clínico, cirúrgico ou angioplastia.

O tratamento clínico requer controle dos fatores de risco, a utilização de medicamentos e o acompanhamento periódico do cardiologista. É indicado quando a doença é menos intensa e causa pouca incapacitação ou como tratamento paliativo para os casos em que a cirurgia é contra-indicada devido às condições das artérias e do músculo cardíaco.

O tratamento cirúrgico mais difundido atualmente é a revascularização do miocárdio com ponte de safena ou com artéria torácica interna, também conhecida como artéria mamária. Consiste em interpor um segmento da veia da perna (safena) do próprio indivíduo entre a artéria aorta e a coronária lesada ou fazer uma anastomose término lateral na artéria coronária lesada, assegurando- 
se assim um adequado fluxo sangüíneo à zona do músculo cardíaco, que antes da cirurgia não recebia sangue suficiente.

A angioplastia consiste em um procedimento que visa desobstruir a artéria por meio de um cateter com dispositivo acoplado à sua extremidade; é geralmente complementada com implante de "stent". Este procedimento só é utilizado em casos que preencham uma série de requisitos, como qualidade e integridade das artérias e extensão da lesão.

Cada indicação terapêutica acarreta um impacto psicológico no paciente e sua intensidade dependerá de diversos fatores como características de personalidade, formas de enfrentamento que o paciente utiliza em situações de crise, representação interna da doença e presença de antecedentes depressivos.

\subsection{DOENÇA ARTERIAL CORONÁRIA: ASPECTOS EMOCIONAIS}

A DAC acarreta importantes implicações emocionais que interferirão significativamente na qualidade de vida, pois ao promover comprometimento geral do indivíduo, afeta-o nos segmentos afetivo-emocional, intelectual e social; além do mais, por ser uma afecção ameaçadora, gera medo, ansiedade e insegurança, sinalizando para o indivíduo sua vulnerabilidade e finitude. De acordo com a personalidade do paciente e com a intensidade da doença somática as respostas emocionais caracterizam-se por atitudes passivas e regressivas, acarretando perda de independência e autonomia; outras vezes, há comportamentos de oposição, animosidade e desconfiança. Acrescenta-se ainda a mudança de papéis sociais que a cardiopatia promove no âmbito familiar, profissional e social (FAVARATO, 2000). Assim, a cronicidade física pode-se somar a psicológica, 
dependendo de como cada indivíduo lidará com a informação de ser portador de doença crônica. Didaticamente, três são as formas de se lidar com a realidade da doença: negação da cronicidade, elaboração deste fato e sua integração ao viver, e por fim, cronificação psicológica, ou seja, viver em torno da doença.

A noção de uma associação entre emoções e função cardíaca é antiga. De fato, William Osler em 1892 descreveu pacientes portadores de DAC como pessoas que trabalham em sua capacidade máxima, incessantemente, buscando sucesso na vida comercial, profissional ou política (apud HAYNES et al, 1980).

A integração de fatores psicológicos como contribuintes para o desenvolvimento da doença arterial coronária foi muito ressaltada com o trabalho dos cardiologistas Meyer Friedman e Ray Rosenman. Na década de 50 eles definiram o padrão de comportamento denominado "tipo A" que se relaciona com a presença de doença coronariana e que se caracteriza por elevada competitividade, hostilidade, impaciência, inquietação, tensão da musculatura facial, discurso explosivo e uma sensação crônica de urgência de tempo, gerando aceleração do pensamento e das ações (FRIEDMAN e ROSENMAN, 1959).

Nessa linha de pesquisa a literatura tem desvelado estudos que relacionam traços de caráter individual com a DAC; assim, a hostilidade, maior atributo do padrão de personalidade "tipo A" tem merecido especial atenção como o principal elemento dessa construção de personalidade. A hostilidade interfere nos relacionamentos interpessoais e inclui traços como raiva, cinismo e desconfiança (KING, 1997).

O estresse crônico relacionado à DAC tem sido amplamente estudado, destacando-se aquele ligado à tensão no trabalho com alta demanda, baixo poder 
de decisão, pouca recompensa e ausência de controle sobre o trabalho (RAHE, 1974).

O acúmulo de situações estressantes no dia a dia e sua possível relação com a DAC estimulou HOLMES e RAHE (1967) a desenvolverem um questionário denominado "Questionário de eventos vitais" que visa identificar os acontecimentos ocorridos no último ano, tais como morte do parceiro, divórcio e perda de emprego, entre outros; a cada um deles é atribuído um valor. Baseado nesse questionário, RAHE et al (1974) observaram nítida associação entre infarto do miocárdio e morte súbita no período de seis meses após a ocorrência dessas situações estressantes.

Estudos epidemiológicos recentes demonstraram de forma consistente uma relação significativa entre episódios de depressão maior e incidência de eventos cardíacos (SCHLEIFER et al, 1989). Por outro lado, sabe-se que a presença de sintomas depressivos, na ausência de diagnóstico de depressão maior, também associa-se a elevado risco de eventos cardíacos; além do mais, há uma nítida relação entre magnitude da depressão e evento cardíaco (ANDA et al, 1993).

ROZANSKI et al (1999) relataram que há cinco fatores psicossociais que contribuem de forma significativa para a etiopatogenia e expressão DAC: depressão, ansiedade, personalidade competitiva, isolamento social e estresse crônico.

\subsection{DOENÇA ARTERIAL CORONÁRIA: DIFERENÇA ENTRE GÊNEROS.}

Aspecto importante a salientar é que a DAC é reconhecida há muitos anos como a causa mais importante de morte e incapacitação entre os homens. Porém, o 
reconhecimento pela comunidade médica de que as doenças cardiovasculares não se restringem a um problema apenas masculino, foi da maior importância. Não que emergisse um novo padrão de mortalidade e morbidade, mas somente o reconhecimento tardio de uma realidade (LOTUFO, 1996).

O infarto agudo do miocárdio (IAM) é a principal causa de morte em mulheres após os 40 anos de idade. Embora ocorra nos homens em média dez anos antes, o prognóstico após IAM é mais sombrio para as mulheres (WENGER, 1996). A possibilidade de morte nas primeiras semanas após infarto é duas vezes maior para as mulheres, além de morrerem mais do que os homens no primeiro ano após IAM. A proteção hormonal contra a doença cardiovascular existente na prémenopausa é eliminada dez anos após a menopausa.

O tema é de tal relevância que nos Estados Unidos foi lançada uma campanha nacional pelo U.S. Department of Health and Human Services para sensibilizar mulheres entre 40 e 60 anos de idade sobre os riscos da doença cardíaca. A campanha denominada "The Heart Truth" (A Verdade sobre o Coração) foi capa da revista Cardiology de julho de 2003 e introduziu como símbolo o vestido vermelho "Red dress" contendo os slogans: "Heart disease doesn't care what you wear" (A doença do coração não se preocupa com o que você veste) e "Being a woman doens't protect you from a heart disease" (Ser mulher não te protege da doença do coração). A campanha foi mobilizada porque uma em cada três mulheres americanas morre de doença cardíaca (NATIONAL INSTITUTE OF HEALTH, 2004).

Além de ser a primeira causa de morte entre as mulheres, sem diferenças de raça ou etnia, atinge idades mais precoces e tem seu risco aumentado na meia-idade. 
A doença cardíaca causa graves danos à saúde, prejudicando a sensação de bem estar e gradativamente a habilidade para desenvolver atividades simples fica comprometida, atingindo de forma significativa a qualidade de vida.

Os fatores de risco para DAC na mulher incluem a hipertensão, o tabagismo, a dislipidemia, o diabetes mellitus, a obesidade, o estresse, o uso de contraceptivo oral após os 35 anos e a menopausa. Além disso, a literatura aponta como fatores adicionais de risco o padrão de comportamento tipo A, estilo de vida sedentário e história familiar de IAM. A patogênese da DAC é similar para homens e mulheres, porém, o diabetes, as concentrações séricas elevadas de triglicérides e baixas de HDL exibem maior impacto no risco da DAC para as mulheres (ROETERS VAN LENNEP et al, 2001). Embora os fatores de risco para DAC sejam semelhantes em homens e mulheres, as manifestações clínicas da doença variam de maneira significante (HAMILTON e SEIDMAN, 1993).

Os estudos revelam que um percentual maior de homens retorna ao trabalho após o primeiro infarto quando comparado às mulheres; tal fato decorre possivelmente delas serem mais idosas na época do infarto (WENGER, 1985). Porém, quando se considera o retorno às atividades domésticas, isto é, o trabalho dentro de casa, não há diferenças entre os gêneros (HAMILTON e SEIDMAN, 1993).

As pesquisas também apontam que as mulheres apresentam sentimentos de serem menos saudáveis que os homens, exibem mais depressão e culpa pela inabilidade de desempenharem as atividades habituais, mas geralmente continuam responsáveis pelo trabalho doméstico (COCHRANE, 1992). 
Em relação a programas de reabilitação cardíaca após IAM pode-se constatar que as mulheres apresentam maiores índices de re-internação hospitalar, menor aderência ao tratamento médico proposto, maior resistência ao envolvimento em programas de reabilitação cardíaca, são mais idosas e tem menor suporte após IAM (COCHRANE, 1992).

Quanto à sexualidade das mulheres, nota-se expressiva diminuição da atividade sexual, com decréscimo na freqüência e referência a sintomas cardíacos durante ou após a atividade sexual; o estudo encontrou também decréscimo da atividade sexual associado a sintomas de ansiedade e depressão (PAPADOPOULOS, 1983).

FAVARATO e ALDRIGHI (2001) em estudo sobre a qualidade de vida em coronariopatas no climatério constataram que tanto nas mulheres com coronariopatia como nas sem doenças associadas ocorre significativa diminuição do desejo sexual após a menopausa, bem como insatisfação com a freqüência e qualidade da vida sexual.

\subsection{DOENÇA ARTERIAL CORONÁRIA E CLIMATÉRIO}

Ao se particularizar o período de climatério emerge um outro fator de risco implicado na gênese da DAC: a menopausa. De fato, estudos epidemiológicos demonstraram claramente que as mulheres apresentam aumento progressivo na incidência da DAC com a idade (KANNEL,1976); assim, após a menopausa a DAC torna-se mais prevalente quando comparada com a pré-menopausa (WENGER, 1996). 
As mulheres habitualmente desenvolvem a DAC dez anos mais tarde que os homens. Além da menopausa, a DAC na mulher associa-se a um grande número e intensidade de outros fatores de risco (MANSUR et al, 2001).

A menopausa é a última menstruação da vida da mulher. Ocorre, em geral, aos 50 anos e seu diagnóstico é sempre retrospectivo, ou seja, há a necessidade de um período de doze meses de ausência de menstruações (ALDRIGHI, 1996).

O climatério, período da vida da mulher situado entre os 40 e 65 anos, constitui a transição entre a fase reprodutiva e aquela em que a reprodução natural não é mais possível. Caracteriza-se por redução progressiva dos estrogênios; assim, com a instabilidade hormonal surgem no climatério manifestações precoces, de médio prazo e tardias, que repercutem biológica, psicológica e socialmente. As precoces compreendem alterações menstruais, ondas de calor, sudorese, calafrios, cefaléia, tonturas, parestesias, palpitações, fadiga, insônia, perda de memória e depressão. Dentre as de médio prazo, destacam-se a secura vaginal, dispareunia, incontinência urinária e perda de colágeno na pele. Entre as tardias, situam-se as alterações metabólicas, que podem redundar na doença cardiovascular e osteoporose (MINISTÉRIO DA SAÚDE, 1994).

Em relação às manifestações precoces, sabe-se que elas decorrem da diminuição da atividade ovariana e subseqüente deficiência hormonal, mas também de dois outros fatores, os sócio-culturais determinados pelo meio ambiente e os psíquicos, dependentes da personalidade da mulher (APPOLINÁRIO, 1992).

Estudo de SKULTANS (1979) considera que a menopausa se constitui em um "rito de passagem", ou seja, a mulher assume outro papel social. Assim, aquelas que atribuem pouca importância à menstruação não sentem a mudança de papel que 
desempenham; o autor considera, dessa forma, que a menopausa é mais sóciocultural do que biológica.

Em relação aos aspectos emocionais do climatério deve-se considerar que a menstruação, por indicar simbolicamente fertilidade e saúde, apresenta grande significado por proporcionar não só "status", mas também poder diante da perpetuação da espécie. Seu término pode ser interpretado como o fim da idade saudável, da reprodução e o início do declínio biológico.

As reações emocionais no climatério são variáveis; assim, muitas mulheres vivenciam-no de forma assintomática ou com sintomas inexpressivos, entendendo-o como o início de uma nova etapa, ou seja, a de amadurecimento existencial que Ihes permitirão uma vida com maior segurança e confiança. Outras porém, vivenciam-no de forma negativa e apresentam vários sintomas e queixas psíquicas, destacando-se a irritabilidade, ansiedade, depressão e as disfunções sexuais (alterações do desejo, da excitação e do orgasmo). Os sintomas são mais exacerbados em mulheres que perderam seu papel social e não redefiniram seus objetivos existenciais (ABREU, 1992).

DENNERSTEIN (1978), por sua vez, relatou que fatores da personalidade e tendências ansiosas correlacionam-se com maior número de queixas psicológicas. É interessante considerar as observações de THONET (1985) que encara o climatério como uma forma de transição, semelhante a uma segunda adolescência. Realmente, nestas duas etapas de vida há mudanças hormonais e de adaptação. Assim, no que tange à adaptação, a adolescente enfrenta as modificações com a vitalidade de um organismo em pleno desenvolvimento e com energia de quem tem metas a alcançar, diferentemente da mulher no climatério 
que pode apresentar falta de motivação para adaptar-se a esta nova fase, bem como baixo entusiasmo para alcançar metas. A desmotivação é claramente percebida em mulheres que não possuem novos objetivos existenciais que as estimulem a prosseguir suas vidas.

DEUSTSCH (1944), por sua vez, compara os conflitos da menopausa com os da menarca: relata inquietudes sobre mudanças no corpo, sexualidade e atividade social. Deve-se ressaltar, no entanto, que esses conflitos são variáveis de acordo com a estrutura psicológica da mulher e que não são obrigatórios no climatério (BENEDEK e RUBINSTEIN, 1952).

É interessante considerar que as situações conflituosas observadas no climatério podem comprometer a auto-estima. Isto, talvez, explique-se pela associação do término da capacidade reprodutiva com a velhice e proximidade da morte, entendendo que o climatério passaria a ser um marco de perdas, objetivos, metas, funções sociais e da juventude.

Convém ressaltar que nas sociedades ocidentais, o aspecto físico e a beleza feminina são supervalorizados; sendo compreensível que mudanças nesses atributos acarretem impacto negativo na autopercepção da mulher, gerando preocupação com o envelhecimento corporal.

SCHINDLER (1987) considera que as doenças depressivas são os transtornos psiquiátricos mais prevalentes da metade para a última fase da vida, sendo que as mulheres são mais vulneráveis do que os homens.

A correlação entre depressão e climatério ainda é assunto controverso. Trata-se de questão complexa, pois durante esse período outras inquietudes tornam-se evidentes, tais como o envelhecimento, a morte dos pais, a saída dos filhos de 
casa em busca de independência e a dificuldade no relacionamento conjugal após muitos anos de vida em comum. Essas intercorrências podem provocar uma reavaliação de seus papéis de mãe e mulher, fazendo-a deparar-se com questionamentos relacionados à sua existência pregressa e futura. $\mathrm{O}$ confronto, não raro pela primeira vez, com a questão da própria morte, pode gerar um desequilíbrio em sua estrutura psíquica.

Estudo de FAVARATO e ALDRIGHI (2001) evidenciou que mulheres no climatério após a menopausa, coronariopatas ou não, tendem a apresentar poucos planos para o futuro, com metas e objetivos incertos, além da presença freqüente de conteúdos depressivos.

\subsection{AVALIAÇÃO DE QUALIDADE DE VIDA EM PORTADORES DE DOENÇA ARTERIAL CORONÁRIA}

Qualidade de vida é conceito originário das ciências sociais, resultado de várias medidas provenientes de indicadores biopsicossociais. A quantificação da qualidade de vida deve obedecer aos seguintes tópicos: trabalho/condições de trabalho, recursos econômicos, escolaridade, saúde/acesso aos serviços de saúde, relações familiares, habitação, nutrição e lazer.

Cada um desses tem seus desdobramentos; assim, na análise da saúde, devem ser incluídos cinco conceitos gerais: saúde física, saúde mental, funções sociais, desempenho de papéis e percepção geral da saúde, que permitem uma melhor determinação do desempenho das atividades diárias e do seu bem estar (FLANAGAN, 1982; WARE, 1987). 
A conceituação de qualidade de vida vem sofrendo modificações, partindo-se de uma visão eminentemente biológica para conceitos multidimensionais, onde são incluídas áreas com características mais subjetivas como atividade social, estado psicológico e expectativas sobre o tratamento (FLETCHER, 1987).

ROMANO (1993) enfatiza a necessidade em se diferenciar "nível de vida" e "qualidade de vida". Enquanto nível de vida depende primordialmente de definições e perspectivas políticas, portanto voltado à comunidade como um todo, qualidade de vida é um atributo do indivíduo.

Diversos instrumentos ou índices têm sido propostos e utilizados com a finalidade de avaliar a qualidade de vida de pacientes com os mais diversos problemas de saúde; dois são os mais importantes: os genéricos e os específicos (PATRICK \& DEYO, 1989; KATZ et al, 1992; BARR, 1995; GUYATT, 1995; GUYATT et al, 1997).

Os instrumentos genéricos foram desenvolvidos com a finalidade de refletir sobre o impacto de uma doença na vida de indivíduos em uma ampla variedade de populações; avaliam aspectos relativos à função, disfunção e desconforto físico e emocional.

Os instrumentos específicos são capazes de avaliar de forma individual e específica determinados aspectos da qualidade de vida, proporcionando uma maior capacidade de detecção de melhora ou piora do aspecto em estudo. Sua principal característica é seu potencial de ser sensível às alterações, ou seja, a capacidade que possui de detectar mudanças após uma determinada intervenção. De acordo com GUYATT (1995) podem ser específicos para uma determinada 
função (capacidade física, sono, função sexual), para uma determinada população (idosos, jovens) e para uma determinada alteração (dor).

Um dos instrumentos desenvolvidos para avaliar a qualidade de vida na área da saúde é o questionário genérico de avaliação de qualidade de vida, denominado "Medical Outcomes study 36-Item Short-Form Health Survey" (SF-36). Por ser um instrumento que possibilita a obtenção de dados objetivos sobre componentes físicos e mentais tem sido muito utilizado na literatura mundial. Em nosso meio foi empregado para avaliação da qualidade de vida em portadores de doenças crônicas reumatológicas (CICONELLI, 1997) e cardiopatias (FAVARATO, 2000), entre outras.

Para comparar a qualidade de vida em tratamentos de doença arterial coronária, dois estudos devem ser citados o "Coronary Angioplasty versus Bypass Revascularization Investigation" (CABRI) e o "Randomized Intervention Treatment of Angina" (RITA-2).

O CABRI é um estudo multicêntrico europeu, que comparou o tratamento cirúrgico e por angioplastia em pacientes coronariopatas. A qualidade de vida após um ano da realização dos procedimentos foi avaliada pelo Nottingham Health Profile e por mais doze outras questões. O estudo mostrou que apesar de não terem sido constatadas diferenças significativas na qualidade de vida após um ano da cirurgia ou da angioplastia, observaram-se resultados mais favoráveis em relação à condição energética nos indivíduos submetidos a cirurgia (WAHRBORG, 1999).

O RITA-2 avaliou a qualidade de vida pelo SF-36 em portadores de angina, submetidos a angioplastia e a tratamento clínico após três meses, um e três anos. 
Concluíram que a angioplastia incrementa substancialmente a percepção da qualidade de vida, especialmente em relação à capacidade funcional e vitalidade, quando comparado ao grupo submetido a tratamento clínico (POCOCK et al, 2000).

Deve-se salientar que nenhum dos estudos avaliou simultaneamente as três formas de tratamento para a DAC, isto é, o tratamento clínico, cirúrgico e por angioplastia, bem como não se compararam possíveis diferenças entre os gêneros masculino e feminino.

Por isso, motivamo-nos a estudá-las. 


\section{OBJETIVOS}

1. Avaliar a qualidade de vida em indivíduos com estenose arterial em múltiplos vasos, angina estável e função ventricular preservada submetidos a uma das três intervenções terapêuticas, ou seja, tratamento clínico, cirurgia de revascularização do miocárdio e angioplastia;

2. Comparar possíveis diferenças entre os gêneros;

3. Analisar os resultados por gênero, particularizando diferentes faixas etárias, de 40 a 50 anos, de 51 a 65 anos e acima de 65 anos. 


\section{MÉTODO}

\subsection{CASUÍSTICA}

Utilizou-se o banco de dados do Medical Angioplasty Surgery Study (MASS II), que avalia comparativamente o tratamento clínico, a angioplastia e a cirurgia em portadores de doença arterial coronária multiarterial, portanto, o presente estudo representa o braço de qualidade de vida do projeto MASS II.

Durante o período de 1995 a 2000, foram selecionados 1114 pacientes do Instituto do Coração - HCFMUSP, portadores de estenose arterial coronária em múltiplos vasos, angina estável e função ventricular preservada, sendo que 611 aceitaram participar do estudo. Após randomização foram encaminhados para tratamento cirúrgico de revascularização de miocárdio (203 pacientes), angioplastia (205 pacientes) e tratamento clínico (203 pacientes).

Foram feitas três avaliações: na fase inicial, aos seis e aos doze meses. Incluíram-se neste estudo os que participaram das três avaliações. Assim, a amostra consistiu de 542 pacientes, sendo 187 submetidos a tratamento clínico, 175 a cirurgia de revascularização do miocárdio e 180 a angioplastia. Dos 542 pacientes 376 eram homens e 166 mulheres.

O estudo foi aprovado pela Comissão Científica do Instituto do Coração e pela Comissão de Normas Éticas e Regulamentares - HCFMUSP. Os participantes, após receber informações detalhadas, assinaram termo de consentimento livre e esclarecido (ANEXO 1). 


\subsection{INSTRUMENTOS}

\subsubsection{QUESTIONÁRIO GENÉRICO DE AVALIAÇÃO DE QUALIDADE DE VIDA} (SF-36)

O SF-36 foi elaborado por WARE e SHERBOUNE (1992) para pesquisar o estado de saúde na prática clínica e nas pesquisas em populações (ANEXO 2). Esse questionário consta de múltiplos itens, podendo ser aplicado a partir dos 14 anos de idade e tem o propósito de avaliar oito domínios divididos em dois grandes componentes: o físico (envolve a capacidade funcional, os aspectos físicos, a dor e o estado geral da saúde) e o mental (abrange a saúde mental, os aspectos emocionais, sociais e a vitalidade). O estado geral da saúde e a vitalidade estão indiretamente relacionados aos dois segmentos.

A seguir, detalha-se a avaliação dos componentes físicos do SF-36. Na capacidade funcional avalia-se a presença e a extensão das limitações relacionadas à capacidade física com três níveis de resposta (muita limitação, pouca e sem limitação); nos aspectos físicos são avaliados as limitações físicas na realização do trabalho e das atividades diárias. A dor é pesquisada por meio de sua intensidade, extensão e/ou interferência nas atividades diárias; o estado geral de saúde é avaliado pela autopercepção.

Em relação aos componentes mentais, a vitalidade é avaliada pela presença de energia e fadiga na realização das atividades da vida diária. Os aspectos sociais são avaliados pela integração do indivíduo nas atividades sociais; os emocionais, pelas dificuldades emocionais que limitam o trabalho e as atividades da vida diária 
e a saúde mental pela presença de ansiedade, depressão, alterações de comportamento ou descontrole emocional e bem-estar psicológico.

O SF-36 inclui ainda um item de avaliação das alterações de saúde ocorridas no período de um ano e que embora não seja usado para pontuar os componentes é de suma importância para o conhecimento da doença do paciente.

Para avaliação de seus resultados, é dado um escore para cada questão que posteriormente são transformados em uma escala de zero a cem, onde zero corresponde a um pior estado de saúde e cem a um melhor, sendo analisado cada dimensão em separado.

Apesar do SF-36 ter sido elaborado para ser um instrumento auto-administrável, a aplicação em nossa população foi realizada por meio de entrevistas, em função da escolaridade dos pacientes.

Tal fato baseia-se nas observações de WEINBERGER et al (1996), que ao compararem várias formas de aplicação do SF-36, ou seja, por meio de telefonemas, entrevistas ou pela forma auto-administrável observaram resultados semelhantes entre os três. Porém, no que se refere à preferência dos pacientes, a forma de aplicação pela entrevista foi a principal escolha $(70 \%)$, seguida pela auto-administrável (20\%) e pelos telefonemas (10\%).

O SF-36 foi traduzido para o português e validado para nossa população (CICONELLI, 1997). Foi aplicado por dois enfermeiros treinados, visando garantir uniformidade na aplicação, em três momentos: no início do tratamento, aos seis e doze meses após o procedimento. 


\subsubsection{QUESTIONÁRIO DE INVESTIGAÇÃO DO PERFIL DEMOGRÁFICO}

O questionário de investigação do perfil demográfico teve por objetivo coletar dados sobre escolaridade, estado conjugal, vida profissional e relação com o trabalho desenvolvido (ANEXO 3). Buscou também avaliar a ocorrência de mudanças relacionadas à doença na esfera do trabalho, da situação econômica e nas perspectivas profissionais, bem como se tais mudanças foram positivas ou negativas do ponto de vista dos pacientes.

\subsection{PROCEDIMENTOS ESTATÍSTICOS}

Para comparação dos aspectos clínicos e perfil demográfico utilizou-se o teste paramétrico ANOVA para as variáveis de distribuição normal e o qui-quadrado para as variáveis sem distribuição normal.

Os resultados do SF-36 foram apresentados por média e comparados pelo teste ANOVA para as avaliações repetidas. 


\section{RESULTADOS}

O estudo incluiu 542 pacientes, 376 homens $(58,5$ anos $\pm 8,7)$ e 166 mulheres $(61,8$ anos $\pm 9,2)$, sendo que estas apresentaram diferença de idade significativamente maior $(p<0,0001)$.

Foram submetidos a tratamento clínico 187 pacientes, 175 a cirurgia de revascularização do miocárdio e 180 pacientes a angioplastia, com distribuição de sexo e idade apresentados na tabela 1 :

Tabela 1 Distribuição dos pacientes segundo tipo de tratamento e idade.

Clínico Cirúrgico $\quad$ Angioplastia

\begin{tabular}{lrcrcrc} 
& $\mathrm{N}$ & Idade & $\mathrm{N}$ & Idade & $\mathrm{N}$ & Idade \\
\hline Homens & 128 & $58,15 \pm 9,14$ & 128 & $58,88 \pm 8,00$ & 120 & $58,45 \pm 9,08$ \\
& & & & & & \\
Mulheres & 59 & $62,43 \pm 9,85$ & 47 & $60,79 \pm 8,64$ & 60 & $61,94 \pm 9,15$ \\
& & & & & & \\
\hline
\end{tabular}

Objetivando-se maior clareza na apresentação dos resultados, subdividiu-se em três partes:

4.1 Dados do perfil demográfico: diferenciação entre gêneros.

4.2Qualidade de vida: comparação entre os resultados obtidos por pacientes submetidos aos tratamentos clínico, cirúrgico ou por angioplastia.

4.3 Qualidade de vida: comparação entre os resultados obtidos por homens e mulheres, particularizando-se diferentes faixas etárias (40 a 50 anos; 51 a 65 anos e acima de 65 anos). 


\subsection{Dados do perfil demográfico: diferenciação entre gêneros.}

Os dados do perfil demográfico demonstram que $69,8 \%$ dos pacientes apresentaram escolaridade até primeiro grau incompleto, sendo $66,7 \%$ dos homens e $77,7 \%$ das mulheres havendo portanto uma diferença significativa entre os gêneros $(p=0,008)$, O nível universitário foi encontrado apenas entre os homens $(9,8 \%)$ (Tabela 2$)$.

Tabela 2 - Distribuição dos pacientes segundo escolaridade.

\begin{tabular}{|c|c|c|c|c|c|c|c|c|c|c|c|c|c|c|c|c|}
\hline & \multicolumn{2}{|c|}{ Analfabeto } & \multicolumn{2}{|c|}{ Semi-alfab } & \multicolumn{2}{|c|}{$1^{\circ} \mathrm{gr}$. Incom } & \multicolumn{2}{|c|}{$1^{\circ} \mathrm{gr}$ Comp } & \multicolumn{2}{|c|}{$2^{\circ} \mathrm{gr}$ incop } & \multicolumn{2}{|c|}{$2^{\circ} \mathrm{gr}$ comp } & \multicolumn{2}{|c|}{ Superior } & \multicolumn{2}{|c|}{ Total } \\
\hline & $\mathrm{N}$ & $\%$ & $\mathrm{~N}$ & $\%$ & $\mathrm{~N}$ & $\%$ & $\mathrm{~N}$ & $\%$ & $\mathrm{~N}$ & $\%$ & $\mathrm{~N}$ & & $\mathrm{~N}$ & $\%$ & & $\%$ \\
\hline Hom & 15 & 4,0 & 25 & 6,6 & 209 & 55,6 & 17 & 4,5 & 16 & 4,3 & 57 & 15,2 & 37 & 9,8 & 376 & 100 \\
\hline $\mathrm{Mul}$ & 25 & 15,1 & 18 & 10,8 & 86 & 51,8 & 15 & 9,0 & 10 & 6,0 & 12 & 7,2 & 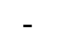 & & 166 & 100 \\
\hline Total & 40 & 7,4 & 43 & 8,0 & 295 & 54,4 & 32 & 6,0 & 26 & 4,8 & 69 & 12,7 & 37 & 6,8 & 542 & 100 \\
\hline
\end{tabular}

Quanto ao estado civil, $82,7 \%$ dos homens eram casados, diferenciando-se das mulheres em que $53,6 \%$ eram casadas $(p<0,000001)$. Diferença significativa encontramos também em relação a viuvez, foram observadas $31,3 \%$ de viúvas e apenas $2,1 \%$ de viúvos $(p<0,000001)$ (Tabela 3$)$.

Tabela 3 - Distribuição dos pacientes segundo estado civil.

\begin{tabular}{lrccccccccccc}
\hline & \multicolumn{2}{c}{ Casado } & \multicolumn{2}{c}{ Amasiado } & \multicolumn{2}{c}{ Solteiro } & \multicolumn{2}{c}{ Separado } & \multicolumn{2}{c}{ Viúvo } & \multicolumn{3}{c}{ Total } \\
& $\mathrm{N}$ & $\%$ & $\mathrm{~N}$ & $\%$ & $\mathrm{~N}$ & $\%$ & $\mathrm{~N}$ & $\%$ & $\mathrm{~N}$ & $\%$ & $\mathrm{~N}$ & $\%$ \\
\hline Homens & 311 & $82,7^{*}$ & 25 & 6,6 & 14 & 3,7 & 18 & 4,8 & 8 & 2,1 & 376 & 100 \\
Mulheres & 89 & 53,6 & 01 & 0,6 & 08 & 4,8 & 16 & 9,6 & 52 & $31,3^{* *}$ & 166 & 100 \\
Total & 400 & 73,9 & 26 & 4,8 & 22 & 4,1 & 34 & 6,3 & 60 & 11,1 & 542 & 100 \\
\hline${ }^{*} p<0,000001$ & ${ }^{* *} \mathrm{p}<0,000001$ & & & & & & & & &
\end{tabular}

A qualificação profissional apontou que $71,1 \%$ das mulheres não tinham atividade profissional, o que diferiu dos homens em que apenas 25,5\% encontravam-se nessa situação. A qualificação da mão de obra foi outro ponto que mereceu 
destaque, $43,9 \%$ dos homens e $11,3 \%$ das mulheres eram mão de obra qualificada (Tabela 4).

Tabela 4 - Distribuição dos pacientes segundo qualificação profissional

\begin{tabular}{lrcrrrrrrrr}
\hline & \multicolumn{2}{c}{ Sem Ativ. Prof } & \multicolumn{2}{c}{ Mão obra desquali } & \multicolumn{2}{c}{ Mão obra qualifi } & \multicolumn{2}{c}{ Prof especializado } & \multicolumn{2}{c}{ Total } \\
& $\mathrm{N}$ & $\%$ & $\mathrm{~N}$ & $\%$ & \multicolumn{1}{c}{$\mathrm{N}$} & $\%$ & $\mathrm{~N}$ & $\%$ & $\mathrm{~N}$ & $\%$ \\
\hline Homens & 95 & 25,5 & 58 & 15,4 & 165 & 43,9 & 58 & 15,4 & 376 & 100 \\
Mulheres & 113 & 71,1 & 26 & 16,4 & 25 & 11,3 & 02 & 1,3 & 166 & 100 \\
Total & 208 & 38,4 & 84 & 15,5 & 190 & 35,1 & 60 & 11,1 & 542 & 100 \\
\hline
\end{tabular}

A avaliação que os pacientes fizeram a respeito do tipo de trabalho que desenvolviam apontou que $35,6 \%$ dos homens e $31,3 \%$ das mulheres consideraram o trabalho cansativo e 6,9\% dos homens e $12,7 \%$ das mulheres consideraram o trabalho desenvolvido como estimulante (Tabela 5).

Tabela 5 - Distribuição dos pacientes segundo tipo de trabalho desenvolvido

\begin{tabular}{|c|c|c|c|c|c|c|c|c|c|c|c|c|c|c|}
\hline & \multicolumn{2}{|c|}{ Repetitivo } & \multicolumn{2}{|c|}{ Estimulante } & \multicolumn{2}{|c|}{ Perigoso } & \multicolumn{2}{|c|}{ Insalubre } & \multicolumn{2}{|c|}{ Cansativo } & \multicolumn{2}{|c|}{ Outro } & \multicolumn{2}{|c|}{ Total } \\
\hline & $\mathrm{N}$ & $\%$ & $\mathrm{~N}$ & $\%$ & $\mathrm{~N}$ & $\%$ & $\mathrm{~N}$ & $\%$ & $\mathrm{~N}$ & $\%$ & $\mathrm{~N}$ & $\%$ & $\mathrm{~N}$ & $\%$ \\
\hline Homens & 86 & 22,9 & 26 & 6,9 & 100 & 26,6 & 12 & 3,2 & 134 & 35,6 & 18 & 4,8 & 376 & 100 \\
\hline Mulheres & 21 & 12,7 & 21 & 12,7 & 16 & 9,6 & 2 & 1,2 & 52 & 31,3 & 54 & 32,5 & 166 & 100 \\
\hline Total & 107 & 19,7 & 47 & 8,7 & 116 & 21,4 & 14 & 2,6 & 186 & 34,3 & 72 & 13,3 & 542 & 100 \\
\hline
\end{tabular}

Em relação à situação de trabalho, homens e mulheres permaneceram relativamente estáveis durante o período de um ano após as intervenções terapêuticas, isto é, o número de pacientes que estavam em benefício da previdência social apresentou um pequeno aumento após seis e doze meses, com um pequeno declínio no número de homens ativos nesse período. Já o número de mulheres ativas teve um pequeno aumento aos seis meses (Tabela 6). 
Tabela 6 - Distribuição dos pacientes segundo situação de trabalho nas fases: inicial, 6 e 12 meses.

\begin{tabular}{|c|c|c|c|c|c|c|c|c|c|c|c|c|}
\hline & \multicolumn{4}{|c|}{ Inicial } & \multicolumn{4}{|c|}{6 meses } & \multicolumn{4}{|c|}{12 meses } \\
\hline & \multicolumn{2}{|c|}{ Ativo } & \multicolumn{2}{|c|}{ Em benefício } & \multicolumn{2}{|c|}{ Ativo } & \multicolumn{2}{|c|}{ Em benefício } & \multicolumn{2}{|c|}{ Ativo } & \multicolumn{2}{|c|}{ Em benefício } \\
\hline & $\mathrm{N}$ & $\%$ & $\mathrm{~N}$ & $\%$ & $\mathrm{~N}$ & $\%$ & $\mathrm{~N}$ & $\%$ & $\mathrm{~N}$ & $\%$ & $\mathrm{~N}$ & $\%$ \\
\hline Homens & 132 & 35,1 & 216 & 57,4 & 131 & 34,8 & 219 & 58,2 & 121 & 32,2 & 230 & 61,2 \\
\hline Mulheres & 18 & 10,8 & 82 & 49,4 & 20 & 12,0 & 87 & 52,4 & 20 & 12,0 & 89 & 53,6 \\
\hline
\end{tabular}

A avaliação dos pacientes sobre a presença de dificuldades na execução do trabalho assinalou que homens e mulheres encontraram menor dificuldade com o passar do tempo após o procedimento (Tabela 7).

Tabela 7 - Distribuição dos pacientes segundo a presença de dificuldades na execução do trabalho.

\begin{tabular}{lcccccc}
\hline & \multicolumn{2}{c}{ Inicial } & \multicolumn{2}{c}{6 meses } & \multicolumn{2}{c}{12 meses } \\
& $\mathrm{N}$ & $\%$ & $\mathrm{~N}$ & $\%$ & $\mathrm{~N}$ & $\%$ \\
\hline Homens & 125 & 33,2 & 77 & 20,5 & 75 & 20,0 \\
Mulheres & 78 & 47,0 & 61 & 36,7 & 47 & 28,3 \\
Total & 203 & 37,6 & 138 & 25,5 & 122 & 22,5 \\
\hline
\end{tabular}

Movimento semelhante encontrou-se em relação às necessidades, crises pessoais e preocupações financeiras dos homens. Já para as mulheres na avaliação de doze meses houve aumento de dificuldade nesses itens.(Tabelas 8 e 9).

Tabela 8 - Distribuição dos pacientes segundo a presença de necessidades e crises pessoais

\begin{tabular}{lrccccc}
\hline & \multicolumn{2}{c}{ Inicial } & \multicolumn{2}{c}{6 meses } & \multicolumn{2}{c}{12 meses } \\
& $\mathrm{N}$ & $\%$ & $\mathrm{~N}$ & $\%$ & $\mathrm{~N}$ & $\%$ \\
\hline Homens & 145 & 38,6 & 97 & 25,8 & 102 & 27,1 \\
Mulheres & 70 & 42,2 & 54 & 32,5 & 61 & 36,8 \\
Total & 215 & 39,7 & 151 & 27,9 & 163 & 30,1 \\
\hline
\end{tabular}


Tabela 9 - Distribuição dos pacientes segundo a presença de preocupações financeiras

\begin{tabular}{lccrccc}
\hline & \multicolumn{2}{c}{ Inicial } & \multicolumn{2}{c}{6 meses } & \multicolumn{2}{c}{12 meses } \\
& $N$ & $\%$ & \multicolumn{1}{c}{$N$} & $\%$ & $\mathrm{~N}$ & $\%$ \\
\hline Homens & 260 & 69,1 & 230 & 61,2 & 218 & 58,0 \\
Mulheres & 104 & 62,7 & 99 & 59,6 & 104 & 62,9 \\
Total & 364 & 67,2 & 329 & 60,7 & 322 & 59,4 \\
\hline
\end{tabular}

A maioria dos pacientes avaliou que não ocorreram mudanças no emprego e ocupação relacionadas à doença no decorrer do primeiro ano após o procedimento, porém uma pequena parcela assinalou mudanças negativas (Tabela 10).

Tabela 10 - Distribuição dos pacientes segundo mudanças no emprego/ocupação relacionadas à doença nas fases inicial, 6 e 12 meses.

\begin{tabular}{|c|c|c|c|c|c|c|c|c|c|c|c|c|}
\hline & \multicolumn{4}{|c|}{ Inicial } & \multicolumn{4}{|c|}{6 meses } & \multicolumn{4}{|c|}{12 meses } \\
\hline & \multicolumn{2}{|c|}{ Não houve } & \multicolumn{2}{|c|}{ Negativa } & \multicolumn{2}{|c|}{ Não houve } & \multicolumn{2}{|c|}{ Negativa } & \multicolumn{2}{|c|}{ Não houve } & \multicolumn{2}{|c|}{ Negativa } \\
\hline & $\mathrm{N}$ & $\%$ & $\Lambda$ & $\%$ & $\mathrm{~N}$ & $\%$ & $\mathrm{~N}$ & $\%$ & $\mathrm{~N}$ & $\%$ & $\mathrm{~N}$ & $\%$ \\
\hline Homens & 315 & 83,8 & 54 & 14,4 & 329 & 87,5 & 39 & 10,4 & 336 & 89,4 & 31 & 8,2 \\
\hline Mulheres & 151 & 91,0 & 12 & 7,2 & 20 & 12,0 & 87 & 52,4 & 158 & 95,2 & 8 & 4,8 \\
\hline
\end{tabular}

Em relação a mudanças na renda relacionadas à doença observou-se que houve maior impacto negativo na fase inicial, que é atenuado aos seis e dozes meses após os procedimentos (Tabela 11).

Tabela 11 - Distribuição dos pacientes segundo mudanças no nível de renda relacionadas à doença nas fases inicial, 6 e 12 meses.

\begin{tabular}{|c|c|c|c|c|c|c|c|c|c|c|c|c|}
\hline & \multicolumn{4}{|c|}{ Inicial } & \multicolumn{4}{|c|}{6 meses } & \multicolumn{4}{|c|}{12 meses } \\
\hline & \multicolumn{2}{|c|}{ Não houve } & \multicolumn{2}{|c|}{ Negativa } & \multicolumn{2}{|c|}{ Não houve } & \multicolumn{2}{|c|}{ Negativa } & \multicolumn{2}{|c|}{ Não houve } & \multicolumn{2}{|c|}{ Negativa } \\
\hline & $\mathrm{N}$ & $\%$ & $\mathrm{~N}$ & $\%$ & $N$ & $\%$ & $\mathrm{~N}$ & $\%$ & $\mathrm{~N}$ & $\%$ & $N$ & $\%$ \\
\hline Homens & 242 & 64,4 & 129 & 34,3 & 293 & 77,9 & 73 & 19,4 & 298 & 79,34 & 67 & 17,8 \\
\hline Mulheres & 139 & 83,7 & 27 & 16,3 & 148 & 89,1 & 15 & 9,0 & 147 & 88,6 & 17 & 10,2 \\
\hline
\end{tabular}


Movimento semelhante, porém de menor intensidade observou-se nas perspectivas profissionais relacionadas à doença (Tabela 12) e na qualidade do trabalho (Tabela 13).

Tabela 12 - Distribuição dos pacientes segundo mudanças nas perspectivas profissionais relacionadas a doença nas fases inicial, 6 e 12 meses.

\begin{tabular}{|c|c|c|c|c|c|c|c|c|c|c|c|c|}
\hline & \multicolumn{4}{|c|}{ Inicial } & \multicolumn{4}{|c|}{6 meses } & \multicolumn{4}{|c|}{12 meses } \\
\hline & \multicolumn{2}{|c|}{ Não houve } & \multicolumn{2}{|c|}{ Negativa } & \multicolumn{2}{|c|}{ Não houve } & \multicolumn{2}{|c|}{ Negativa } & \multicolumn{2}{|c|}{ Não houve } & \multicolumn{2}{|c|}{ Negativa } \\
\hline & $\mathrm{N}$ & $\%$ & $\mathrm{~N}$ & $\%$ & $\mathrm{~N}$ & $\%$ & $\mathrm{~N}$ & $\%$ & $\mathrm{~N}$ & $\%$ & $\mathrm{~N}$ & $\%$ \\
\hline Homens & 302 & 80,3 & 67 & 17,8 & 329 & 87,5 & 39 & 10,4 & 326 & 86,7 & 38 & 10,1 \\
\hline Mulheres & 155 & 93,4 & 11 & 6,6 & 157 & 94,6 & 07 & 4,2 & 158 & 95,2 & 07 & 4,2 \\
\hline
\end{tabular}

Tabela 13 - Distribuição dos pacientes segundo mudanças qualidade do trabalho relacionadas à doença nas fases inicial, 6 e 12 meses

\begin{tabular}{|c|c|c|c|c|c|c|c|c|c|c|c|c|}
\hline & \multicolumn{4}{|c|}{ Inicial } & \multicolumn{4}{|c|}{6 meses } & \multicolumn{4}{|c|}{12 meses } \\
\hline & \multicolumn{2}{|c|}{ Não houve } & \multicolumn{2}{|c|}{ Negativa } & \multicolumn{2}{|c|}{ Não houve } & \multicolumn{2}{|c|}{ Negativa } & \multicolumn{2}{|c|}{ Não houve } & \multicolumn{2}{|c|}{ Negativa } \\
\hline & $\mathrm{N}$ & $\%$ & $\mathrm{~N}$ & $\%$ & $\mathrm{~N}$ & $\%$ & $\mathrm{~N}$ & $\%$ & $\mathrm{~N}$ & $\%$ & $\mathrm{~N}$ & $\%$ \\
\hline Homens & 294 & 78,2 & 78 & 20,7 & 326 & 86,7 & 45 & 12,0 & 332 & 88,3 & 35 & 9,3 \\
\hline Mulheres & 138 & 83,14 & 27 & 16,3 & 150 & 90,4 & 13 & 7,8 & 152 & 91,6 & 12 & 7,2 \\
\hline
\end{tabular}

A porcentagem de pacientes que tinham fonte de renda proveniente do trabalho diminuiu gradativamente aos seis e doze meses após os procedimentos (Tabela 14), aspecto que coincidiu com o aumento progressivo no número de pacientes em benefício previdenciário apresentado nas tabelas 6 .

Tabela 14 - Distribuição dos pacientes segundo fonte de renda proveniente do trabalho.

\begin{tabular}{lrrrlrl}
\hline & $\mathrm{N}$ & Inicial & \multicolumn{2}{c}{$\mathrm{N}^{6 \text { meses }}$} & \multicolumn{2}{c}{12 meses } \\
\hline Homens & 206 & 54,8 & 190 & 50,5 & 186 & 49,5 \\
Mulheres & 34 & 20,5 & 30 & 18,1 & 25 & 15,1 \\
Total & 240 & 44,3 & 220 & 40,6 & 212 & 39,0 \\
\hline
\end{tabular}


4.2 Qualidade de vida: comparação entre os resultados obtidos por pacientes submetidos aos tratamentos clínico, cirúrgico ou por angioplastia.

Ao comparar-se a qualidade de vida dos pacientes submetidos aos três tipos de intervenção terapêutica constata-se que as mudanças nos resultados nas fases inicial, seis e doze meses foram significativas em todas as dimensões do SF-36 $(p<0,0001)$. Os que realizaram cirurgia de revascularização do miocárdio apresentaram piores resultados na avaliação inicial, porém seis e doze meses após o procedimento ocorreu melhora progressiva, superando os pacientes submetidos a tratamento clínico e por angioplastia em quase todas as dimensões do SF-36. Já os que realizaram angioplastia apresentaram melhor avaliação inicial; porém nas subseqüentes embora apresentem melhora, esta foi de menor intensidade quando comparados aos cirúrgicos. Nos pacientes que receberam tratamento clínico, após a melhora apresentada na avaliação de seis meses, observou-se pequena queda nos resultados como mostra a tabela 15.

Tabela 15 - Distribuição dos resultados do SF-36, segundo tipo de intervenção, nas fases inicial, 6 e 12 meses.

\begin{tabular}{|c|c|c|c|c|c|c|c|c|c|c|}
\hline & \multicolumn{3}{|c|}{ Clínico } & \multicolumn{3}{|c|}{ Cirúrgico } & \multicolumn{3}{|c|}{ Angioplastia } & \multirow[t]{2}{*}{$\mathrm{p}$ (entre gr) } \\
\hline & Inic. & $6 m$ & $12 m$ & Inic. & $6 m$ & $12 m$ & Inic. & $6 m$ & $12 m$ & \\
\hline Cap. Funcional * & 52 & 66 & 65 & 46 & 67 & 73 & 58 & 71 & 73 & 0,002 \\
\hline Aspectos Físicos * & 26 & 45 & 43 & 18 & 41 & 47 & 33 & 44 & 54 & 0,014 \\
\hline Dor * & 64 & 75 & 71 & 59 & 71 & 76 & 66 & 74 & 76 & 0,246 \\
\hline Estado Geral Saúde* & 64 & 73 & 70 & 62 & 73 & 77 & 69 & 76 & 75 & 0,032 \\
\hline Vitalidade * & 57 & 62 & 62 & 56 & 72 & 73 & 65 & 72 & 72 & $<0,0001$ \\
\hline Aspecto Emocional * & 50 & 64 & 66 & 49 & 62 & 67 & 54 & 69 & 67 & 0,316 \\
\hline Aspectos Sociais * & 73 & 79 & 78 & 64 & 79 & 82 & 71 & 80 & 83 & $<0,0001$ \\
\hline Saúde Mental * & 64 & 70 & 69 & 64 & 71 & 74 & 66 & 73 & 73 & 0,216 \\
\hline
\end{tabular}

$* \mathrm{p}<0,0001$ (repetições) 
A figura 1 ilustra as diferenças entre os pacientes submetidos aos diversos tratamentos na fase inicial. Pode-se constatar que os pacientes cirúrgicos apresentaram os piores escores em todas as dimensões, exceto na saúde mental na qual se igualaram aos pacientes clínicos.

Figura 1 - Distribuição dos resultados do SF-36, segundo o tipo de intervenção na fase inicial.

\section{$\square$ Clínico $\square$ Cirúrgico $\square$ Angioplastia}

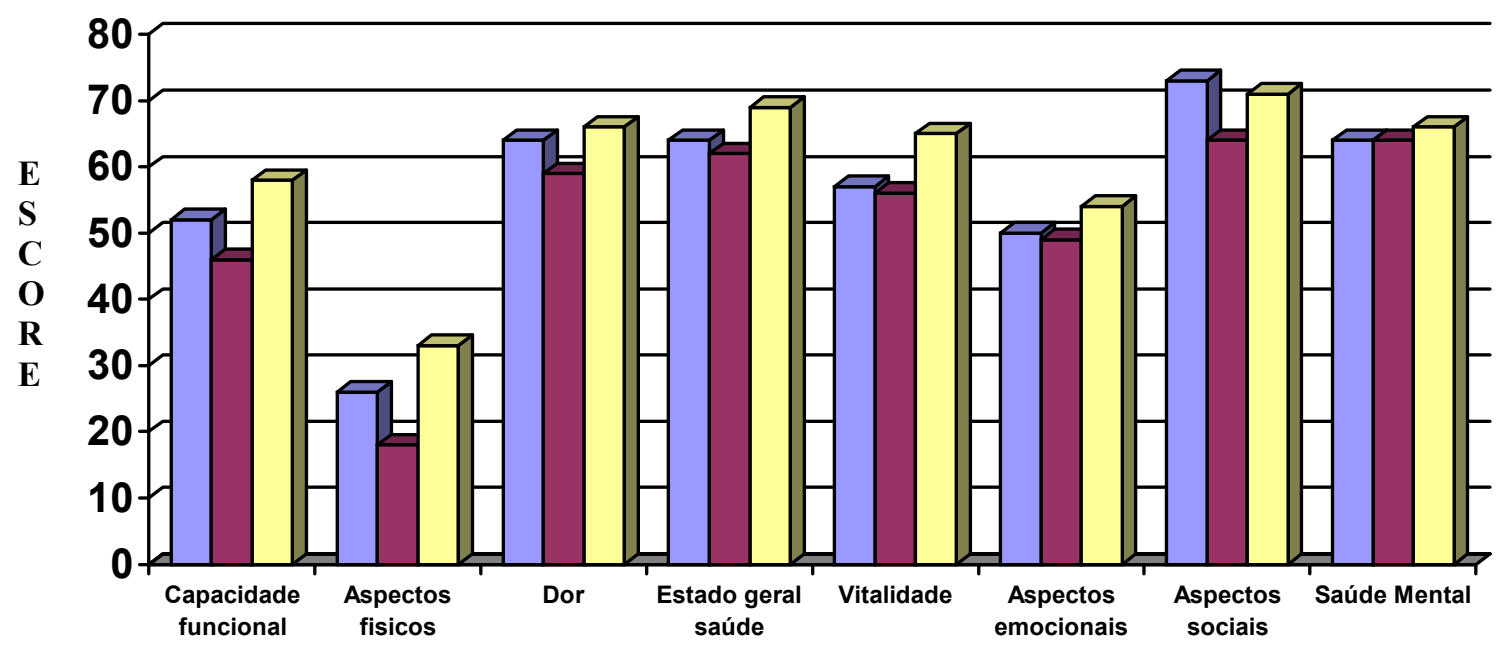

A figura 2 ilustra as diferenças entre os pacientes submetidos aos diversos tratamentos após seis meses do procedimento. Observou-se que os pacientes submetidos aos três procedimentos apresentaram melhora significativa na qualidade de vida após seis meses das intervenções ( $p<0,0001$ para repetições). Porém os cirúrgicos tiveram o aumento mais expressivo, chegando a ultrapassar os escores dos pacientes clínicos em capacidade funcional, vitalidade e saúde mental. 
Figura 2 Distribuição dos resultados do SF-36, segundo o tipo de intervenção após 6 meses.

\section{$\square$ Clínico $\square$ Cirúrgico $\square$ Angioplastia}

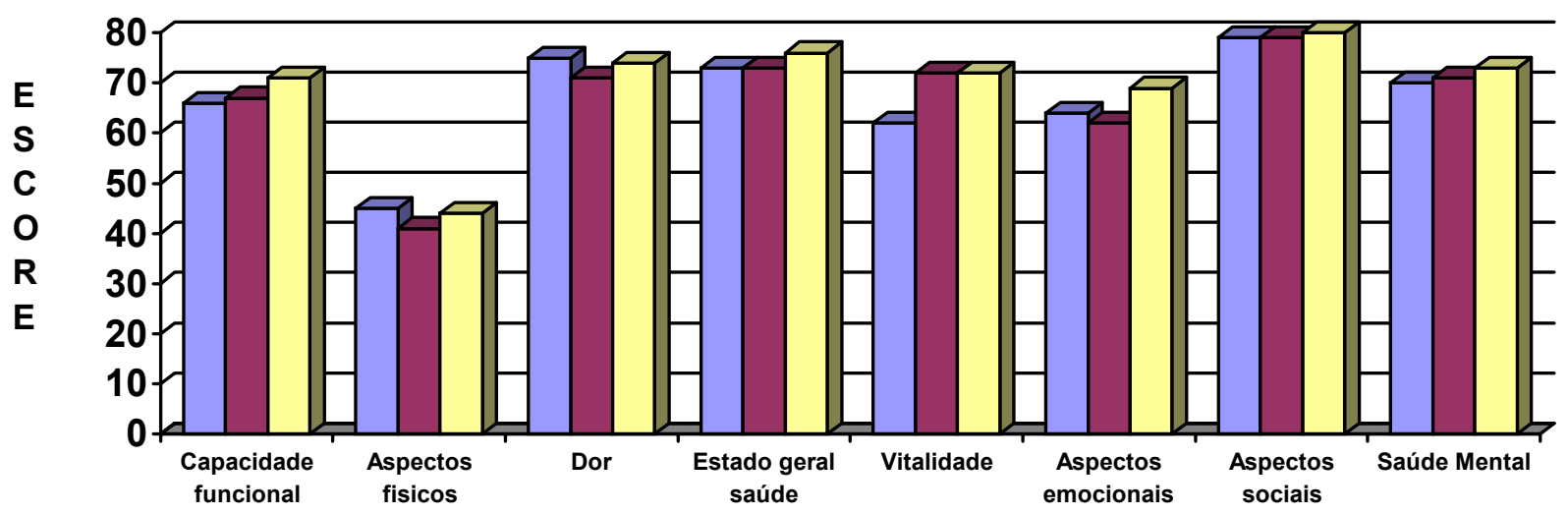

A figura 3 ilustra as diferenças entre os pacientes submetidos aos diversos tratamentos após doze meses do procedimento. Os pacientes clínicos após a melhora obtida da avaliação de seis meses, apresentaram pequena queda nos resultados aos doze meses. Os pacientes cirúrgicos continuaram com melhora progressiva e atingiram os melhores resultados em estado geral de saúde, vitalidade, saúde mental, equiparando-se aos pacientes de angioplastia em capacidade funcional, dor e aspecto emocional. 
Figura 3 Distribuição dos resultados do SF-36, segundo o tipo de intervenção após 12 meses.

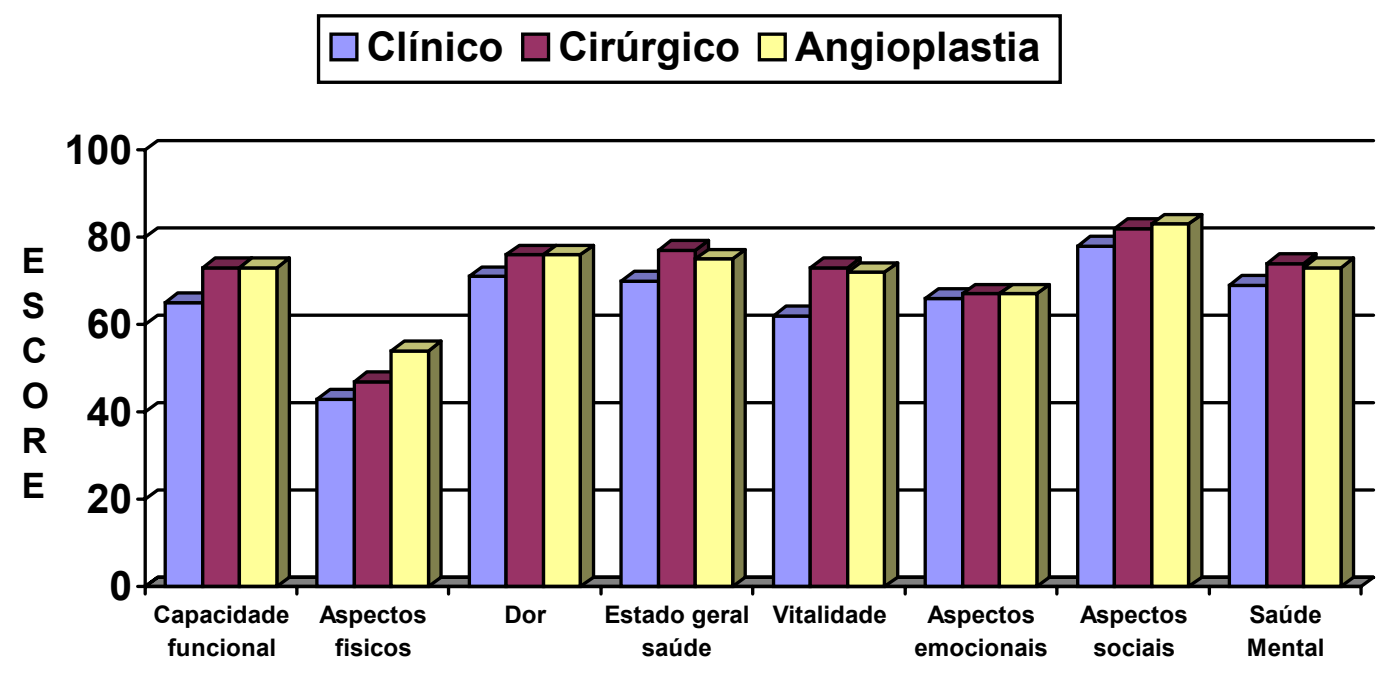

\subsection{Qualidade de vida: comparação entre os resultados obtidos por homens e mulheres, particularizando-se diferentes faixas etárias (40 a 50 anos; 51 a 65 anos e acima de 65 anos).}

Comparando-se os resultados obtidos por homens e mulheres pode-se constatar diferença significativa entre os gêneros. Os homens portadores de DAC apresentaram melhor qualidade de vida no início do tratamento, quando comparados às mulheres e beneficiaram-se progressivamente seis e doze meses após a realização das intervenções terapêuticas, diferenciando-se das mulheres, que apresentaram melhora após seis meses, porém aos doze exibiram queda nos resultados em todas as dimensões (Tabela 16). 
Tabela 16 - Distribuição dos resultados do SF-36, segundo sexo nas fases inicial, 6 e 12 meses.

\begin{tabular}{ccccccccccccccccccc}
\hline Sf-36 & \multicolumn{1}{c}{ C. Func } & \multicolumn{1}{c}{ Asp Fis } & \multicolumn{2}{c}{ Dor } & \multicolumn{2}{c}{ EGS } & \multicolumn{2}{c}{ Vital } & A. & Soc & A. & Emo & \multicolumn{2}{c}{ SM } \\
& H & M & H & M & H & M & H & M & H & M & H & M & H & M & H & M \\
\hline Inicial & 58 & 40 & 28 & 19 & 65 & 57 & 67 & 62 & 62 & 52 & 73 & 61 & 55 & 41 & 68 & 56 \\
$6 \mathrm{~m}$ & 68 & 68 & 44 & 42 & 74 & 73 & 74 & 73 & 72 & 61 & 80 & 79 & 65 & 63 & 72 & 69 \\
$12 \mathrm{~m}$ & 76 & 57 & 53 & 36 & 78 & 66 & 75 & 70 & 73 & 60 & 85 & 70 & 70 & 60 & 76 & 62 \\
\hline
\end{tabular}

A figura 4 ilustra as diferenças de gênero, na fase inicial, na qual os homens apresentaram melhores resultados em todas as dimensões do SF-36.

Figura 4 - Distribuição dos resultados do SF-36, segundo sexo na fase inicial.

\section{$\square$ Homens $\square$ Mulheres}

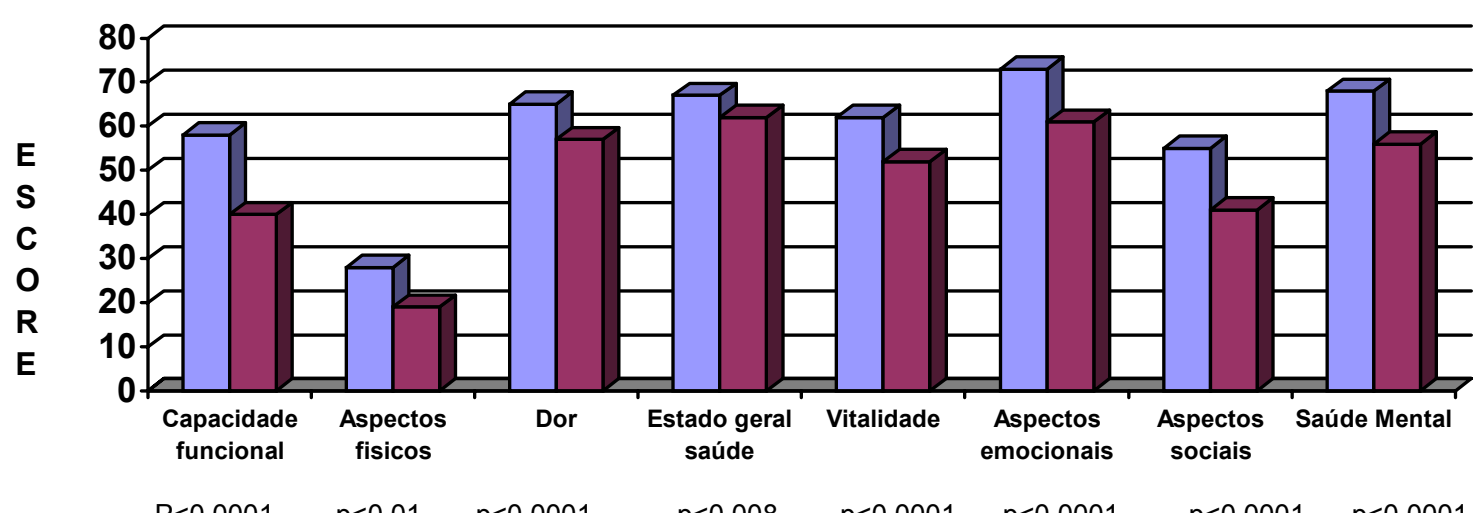


A figura 5 ilustra as diferenças de gênero, após seis meses, na qual as mulheres apresentaram melhora da qualidade de vida em todas as dimensões, aproximando-se dos resultados dos homens, exceto na vitalidade onde houve diferença significativa.

Figura 5 - Distribuição dos resultados do SF-36, segundo sexo, após 6 meses.

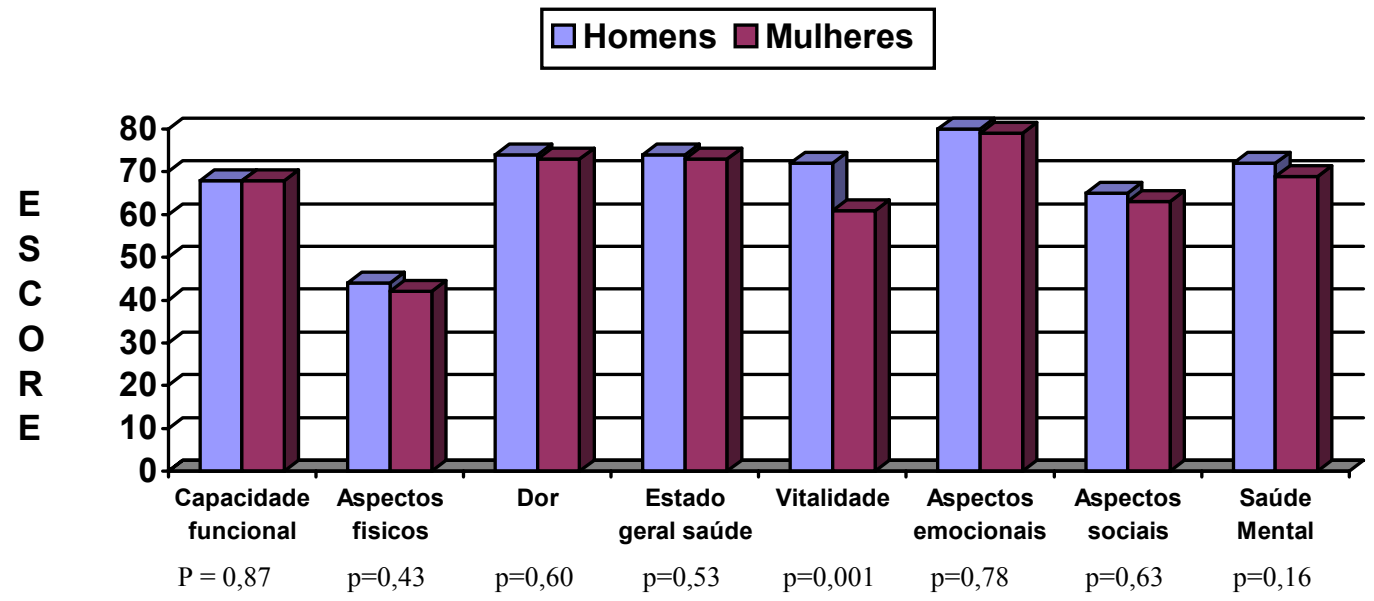

A figura 6 ilustra as diferenças de gênero após doze meses, na qual os homens continuaram a apresentar melhora progressiva na qualidade de vida e as mulheres tiveram queda nos resultados, diferenciando-se dos homens. 
Figura 6 - Distribuição dos resultados do SF-36, segundo sexo, após 12 meses.

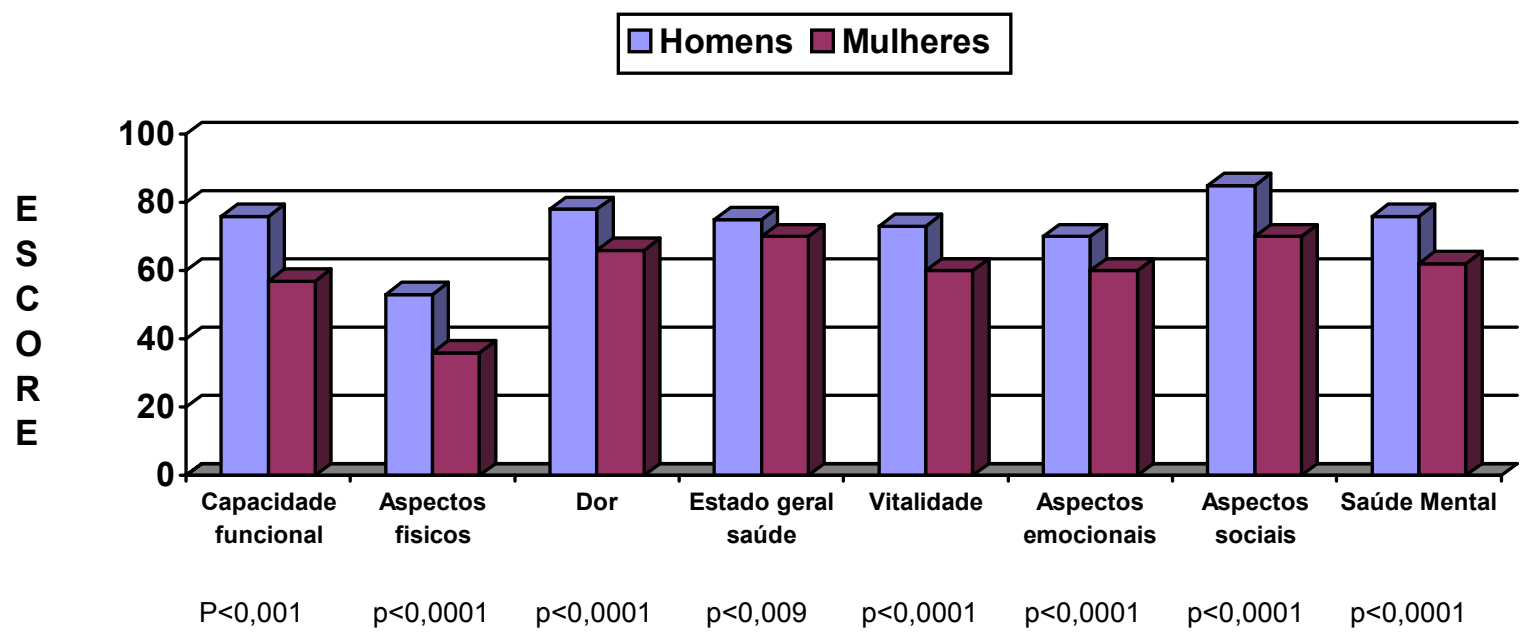

Apresenta-se, a seguir, a média dos resultados obtidos por homens e mulheres nos componentes físicos que envolvem a capacidade funcional, os aspectos físicos, a dor e o estado geral de saúde e nos componentes mentais que incluem a vitalidade, os aspectos sociais, o aspecto emocional e a saúde mental( Figura 7 e 8). Observou-se que o prejuízo na qualidade de vida das mulheres em relação aos homens foi referente, principalmente, aos componentes mentais.

Figura 7 - Distribuição da média dos resultados obtidos nos componentes físicos do SF-36, segundo sexo.

\section{$\square$ Homens $\square$ Mulheres}

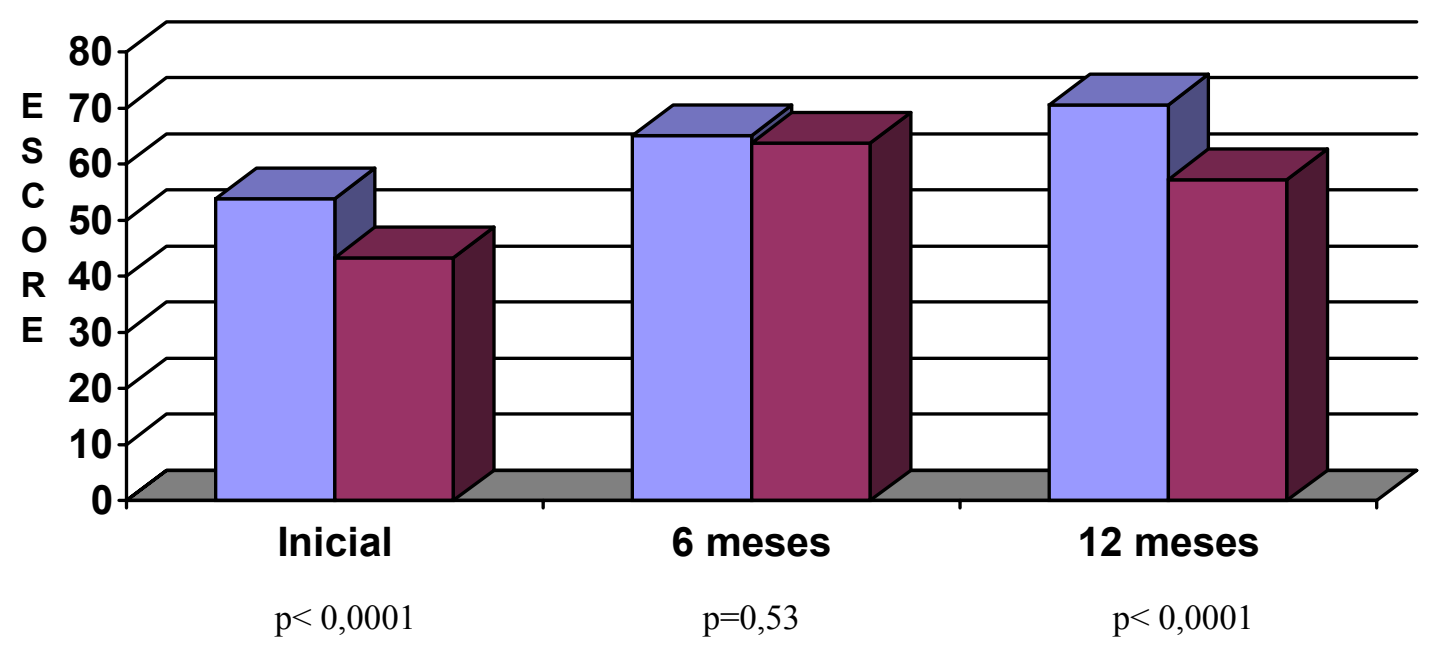


Figura 8 - Distribuição da média dos resultados obtidos nos componentes mentais do SF-36 segundo sexo.

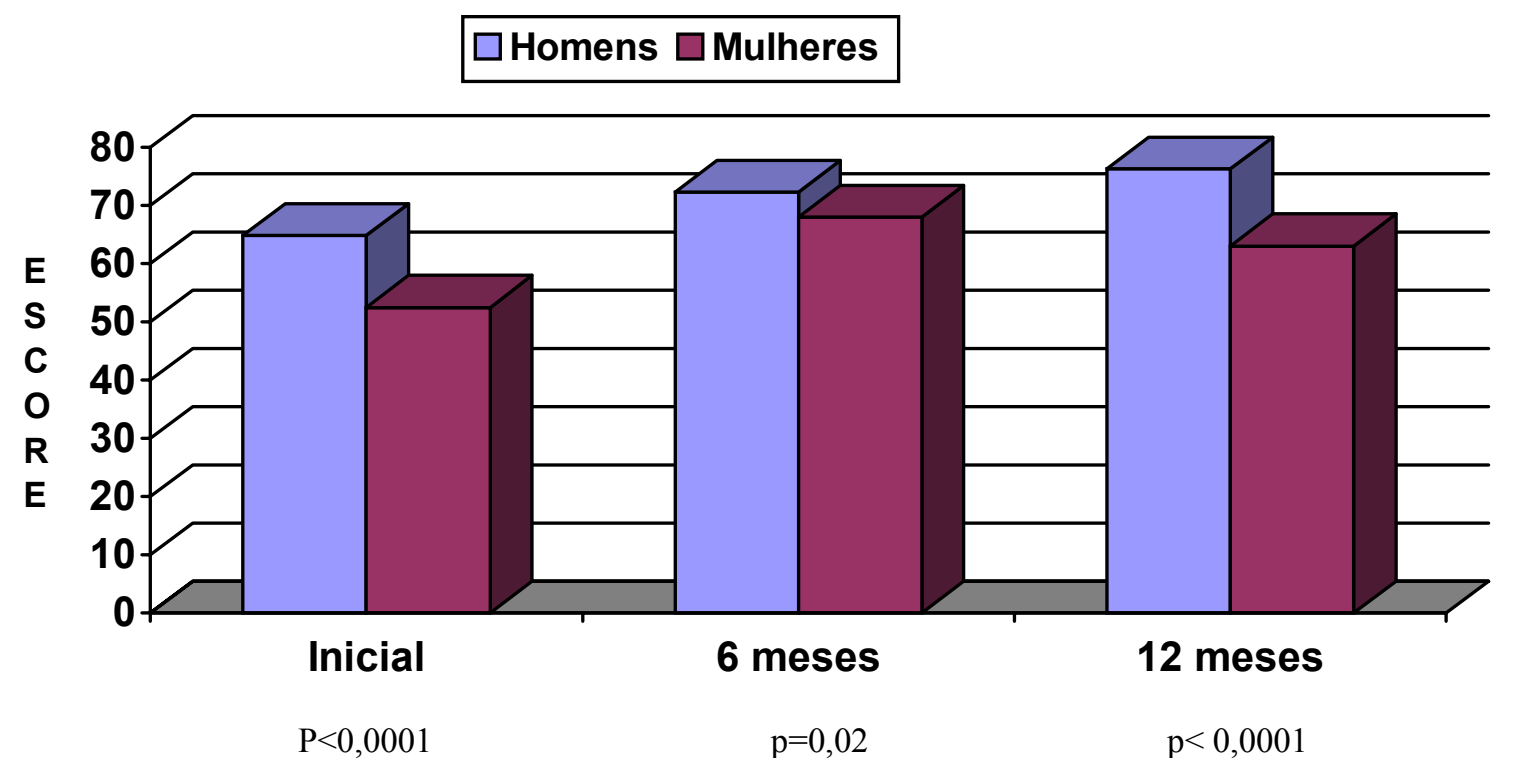

Os resultados foram analisados também por gênero, particularizando-se diferentes faixas etárias, ou seja, 40 a 50 anos, 51 a 65 anos e acima de 65 anos; constatou-se que não houve diferença significativa na evolução dos resultados nas diferentes faixas etárias tanto para homens, quanto para mulheres.

A tabela 17 apresenta os resultados dos pacientes com idade entre 40 e 50 anos.

Tabela 17 - Distribuição dos resultados do SF-36, segundo sexo e idade, entre 40 e 50 anos.

\begin{tabular}{lcccccc}
\hline \multicolumn{1}{c}{ SF-36 } & \multicolumn{3}{c}{ Homens } & \multicolumn{3}{c}{ Mulheres } \\
& Inicial & $6 \mathrm{~m}$ & $12 \mathrm{~m}$ & Inicial & $6 \mathrm{~m}$ & $12 \mathrm{~m}$ \\
\hline Capacidade Funcional & 58 & 72 & 78 & 38 & 65 & 61 \\
Aspectos Físicos & 30 & 53 & 70 & 23 & 35 & 48 \\
Dor & 68 & 76 & 83 & 48 & 78 & 68 \\
Estado Geral de Saúde & 68 & 76 & 77 & 56 & 77 & 71 \\
Vitalidade & 62 & 77 & 75 & 47 & 49 & 55 \\
Aspectos Sociais & 70 & 79 & 91 & 63 & 83 & 70 \\
Aspecto Emocional & 46 & 69 & 79 & 48 & 67 & 71 \\
Saúde Mental & 67 & 69 & 76 & 46 & 73 & 53 \\
\hline
\end{tabular}


A tabela 18 apresenta os resultados dos pacientes com idade entre 51 e 65 anos.

Tabela 18 - Distribuição dos resultados do SF-36, segundo sexo e idade, entre 51 e 65 anos.

\begin{tabular}{lcccccc}
\hline \multicolumn{1}{c}{ SF-36 } & \multicolumn{3}{c}{ Homens } & \multicolumn{3}{c}{ Mulheres } \\
& Inicial & $6 \mathrm{~m}$ & $12 \mathrm{~m}$ & Inicial & $6 \mathrm{~m}$ & $12 \mathrm{~m}$ \\
\hline Capacidade Funcional & 57 & 66 & 76 & 40 & 67 & 61 \\
Aspectos Físicos & 25 & 41 & 48 & 16 & 44 & 36 \\
Dor & 64 & 74 & 77 & 55 & 71 & 64 \\
Estado Geral de Saúde & 65 & 74 & 74 & 62 & 72 & 69 \\
Vitalidade & 60 & 69 & 72 & 50 & 62 & 61 \\
Aspectos Sociais & 73 & 79 & 84 & 59 & 78 & 74 \\
Aspecto Emocional & 56 & 64 & 67 & 39 & 66 & 62 \\
Saúde Mental & 67 & 73 & 76 & 55 & 70 & 64 \\
\hline
\end{tabular}

A tabela 19 apresenta os resultados dos pacientes com idade superior a 65 anos.

Tabela 19 - Distribuição dos resultados do SF-36, segundo sexo e idade superior a 65 anos.

\begin{tabular}{lcccccc}
\hline \multicolumn{1}{c}{ SF-36 } & \multicolumn{3}{c}{ Homens } & \multicolumn{3}{c}{ Mulheres } \\
& Inicial & $6 \mathrm{~m}$ & $12 \mathrm{~m}$ & Inicial & $6 \mathrm{~m}$ & $12 \mathrm{~m}$ \\
\hline Capacidade Funcional & 60 & 67 & 74 & 42 & 71 & 49 \\
Aspectos Físicos & 34 & 46 & 52 & 22 & 42 & 30 \\
Dor & 67 & 73 & 76 & 62 & 73 & 68 \\
Estado Geral de Saúde & 72 & 73 & 77 & 64 & 73 & 73 \\
Vitalidade & 67 & 75 & 75 & 58 & 64 & 61 \\
Aspectos Sociais & 77 & 80 & 86 & 62 & 79 & 66 \\
Aspecto Emocional & 62 & 66 & 68 & 40 & 58 & 53 \\
Saúde Mental & 73 & 73 & 78 & 60 & 66 & 64 \\
\hline
\end{tabular}


A evolução por gênero e faixas etárias são apresentadas a seguir.

Figura 9 - Distribuição dos resultados da capacidade funcional (presença de limitações relacionadas à capacidade física) em homens, segundo faixas etárias.

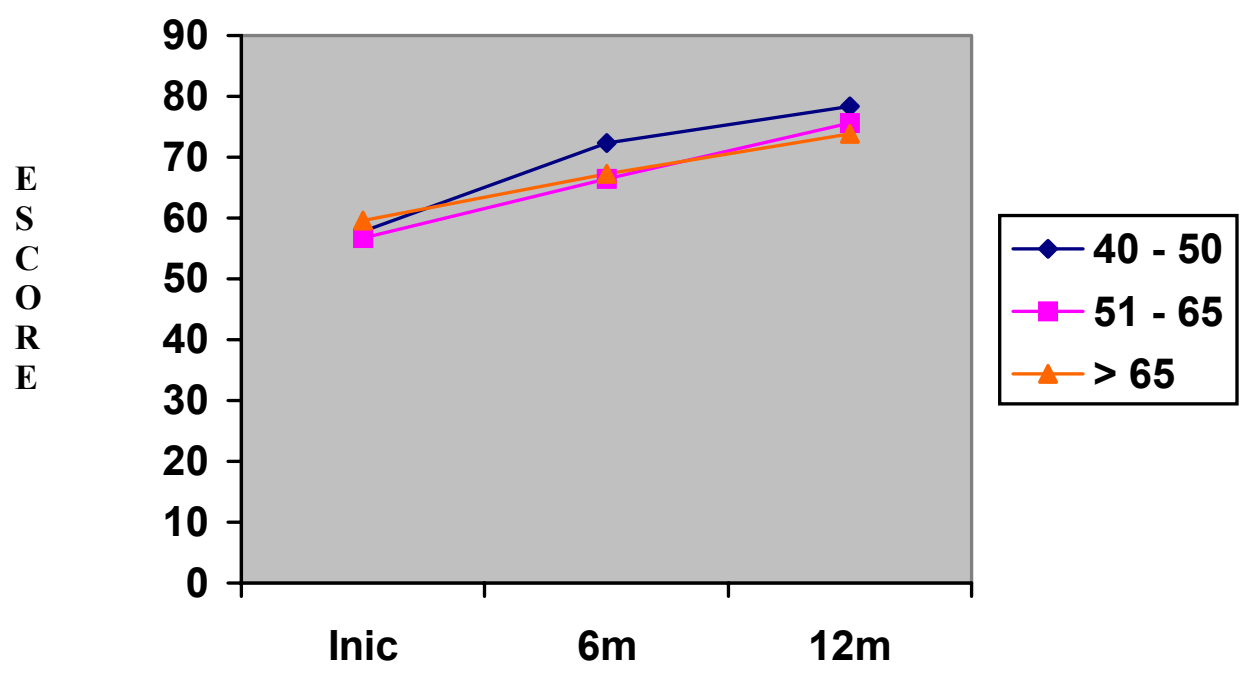

Figura 10 - Distribuição dos resultados da capacidade funcional (presença de limitações relacionadas à capacidade física) em mulheres, segundo faixas etárias.

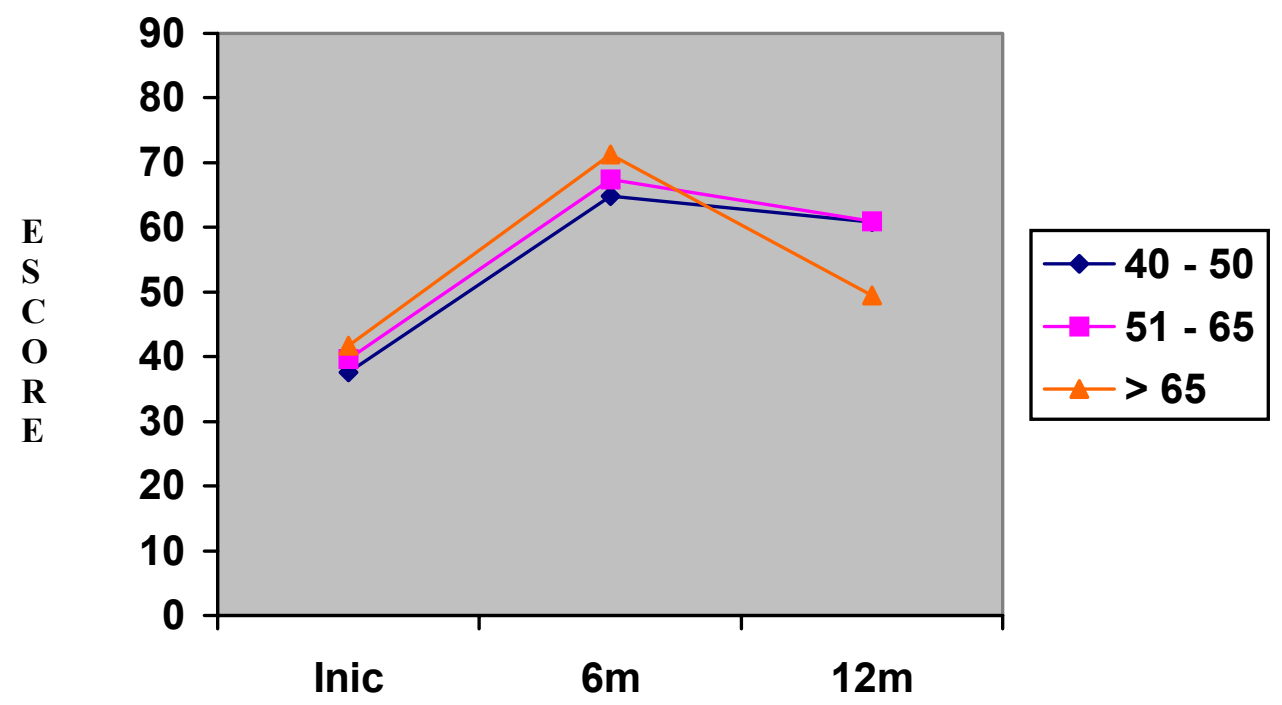


Figura 11 - Distribuição dos resultados dos aspectos físicos (limitações físicas na realização de atividades diárias) em homens, segundo faixas etárias.

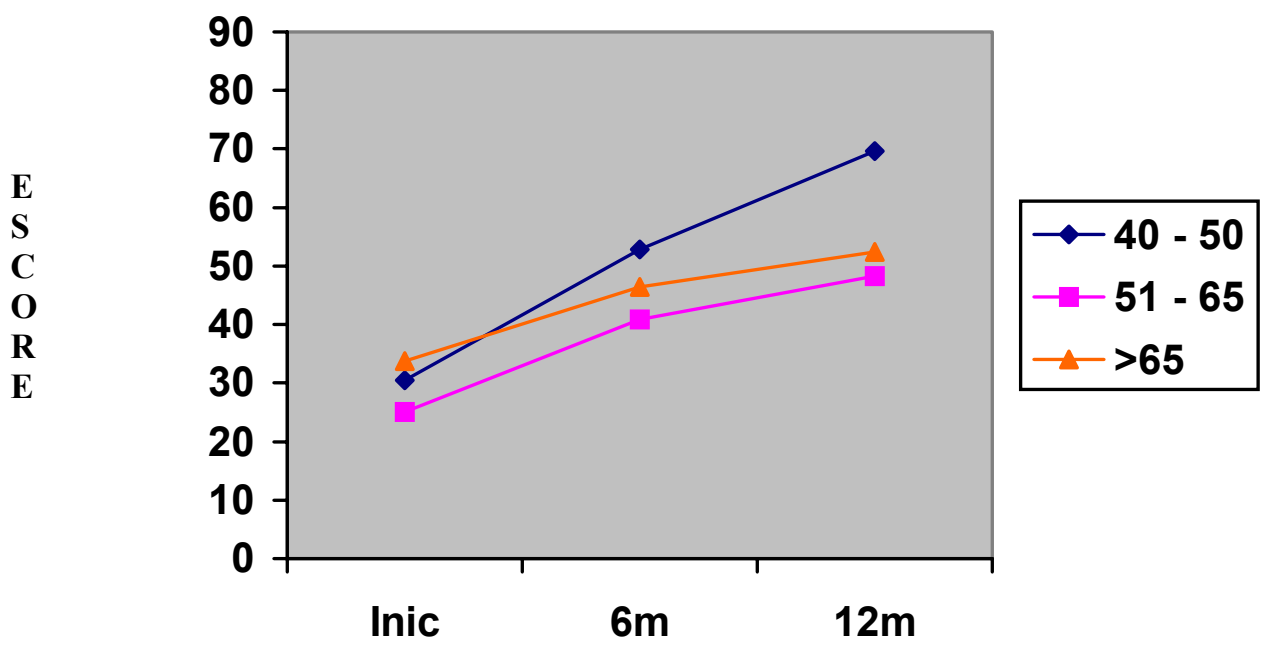

Figura 12 - Distribuição dos resultados dos aspectos físicos (limitações físicas na realização de atividades diárias) em mulheres, segundo faixas etárias.

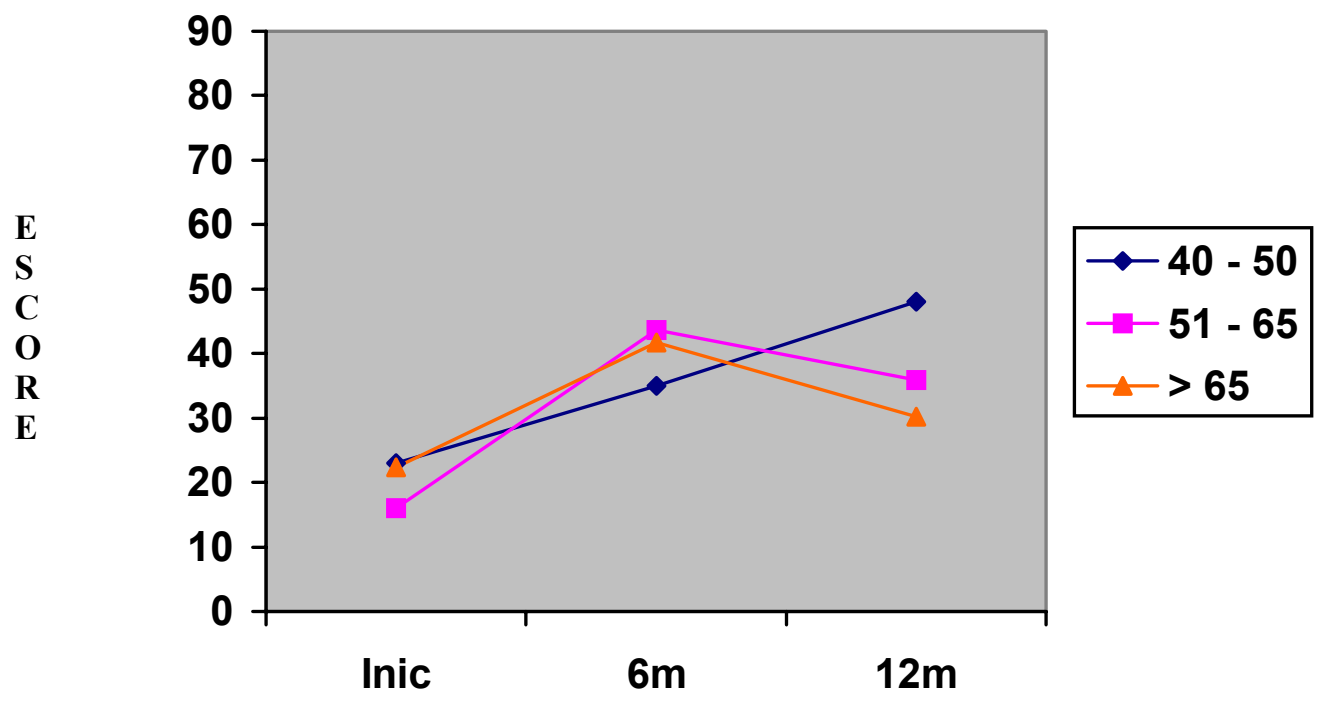


Figura 13 - Distribuição dos resultados da dor (interferência da dor nas atividades diárias) em homens, segundo faixas etárias.

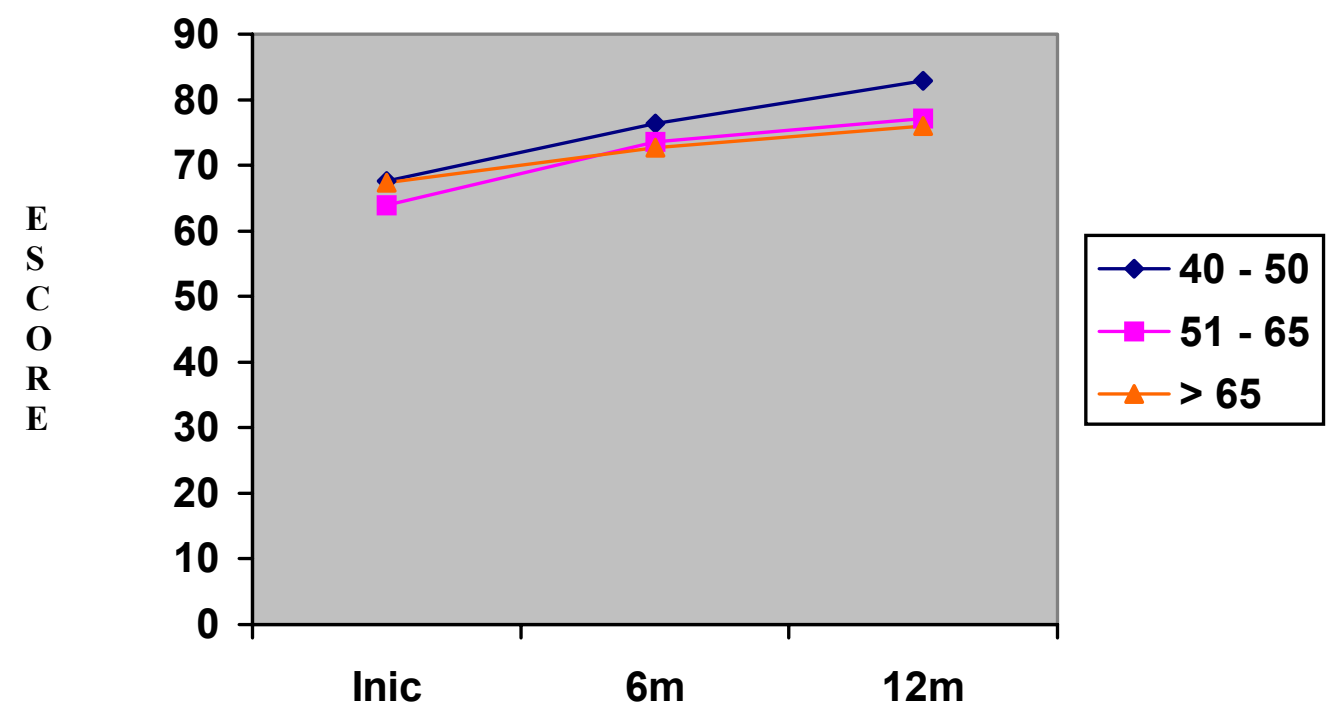

Figura 14 - Distribuição dos resultados da dor (interferência da dor nas atividades diárias) em mulheres, segundo faixas etárias.

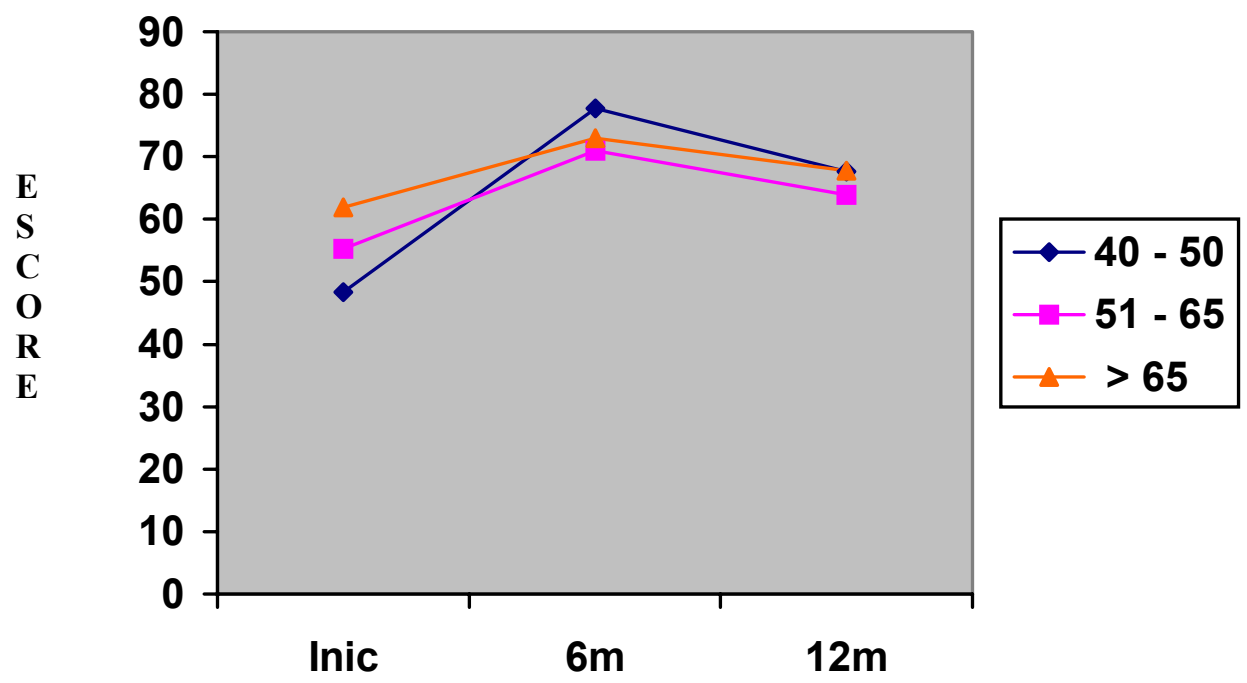


Figura 15 - Distribuição dos resultados de estado geral de saúde (autopercepção da saúde) em homens, segundo faixas etárias.

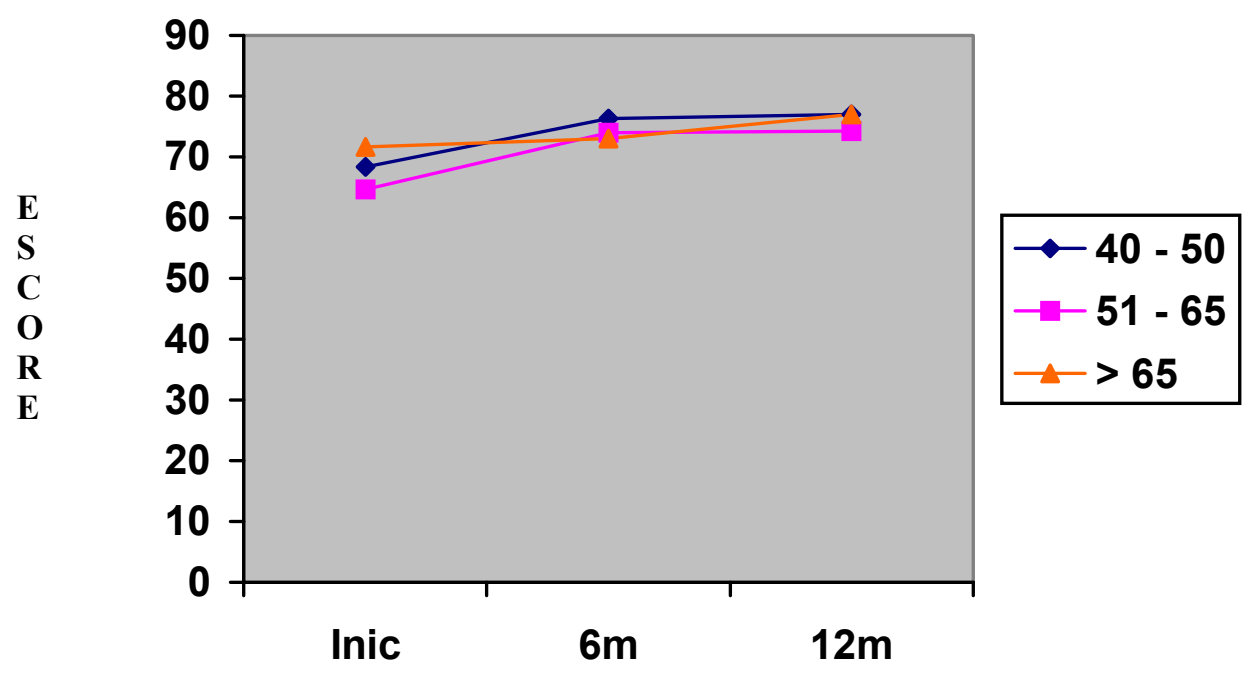

Figura 16 - Distribuição dos resultados de estado geral de saúde (autopercepção da saúde) em mulheres, segundo faixas etárias.

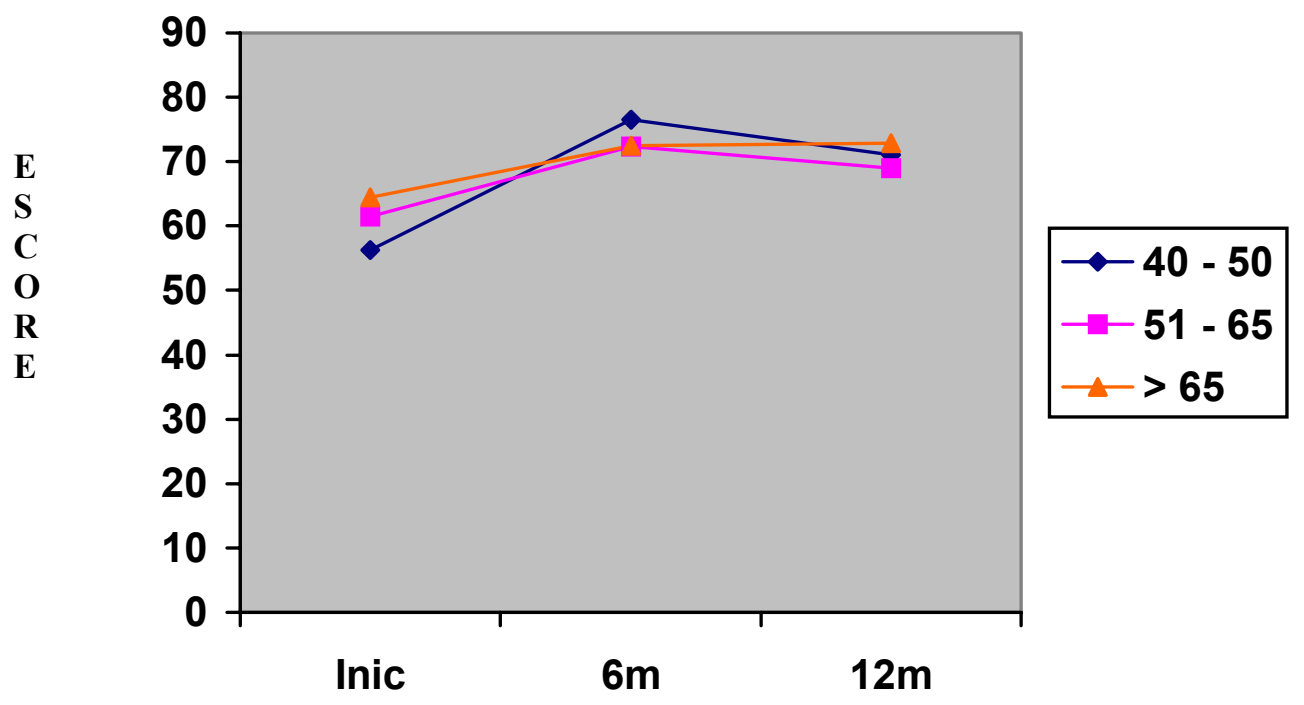


Figura 17 - Distribuição dos resultados de vitalidade (nível de energia e fadiga nas atividades diárias) em homens, segundo faixas etárias.

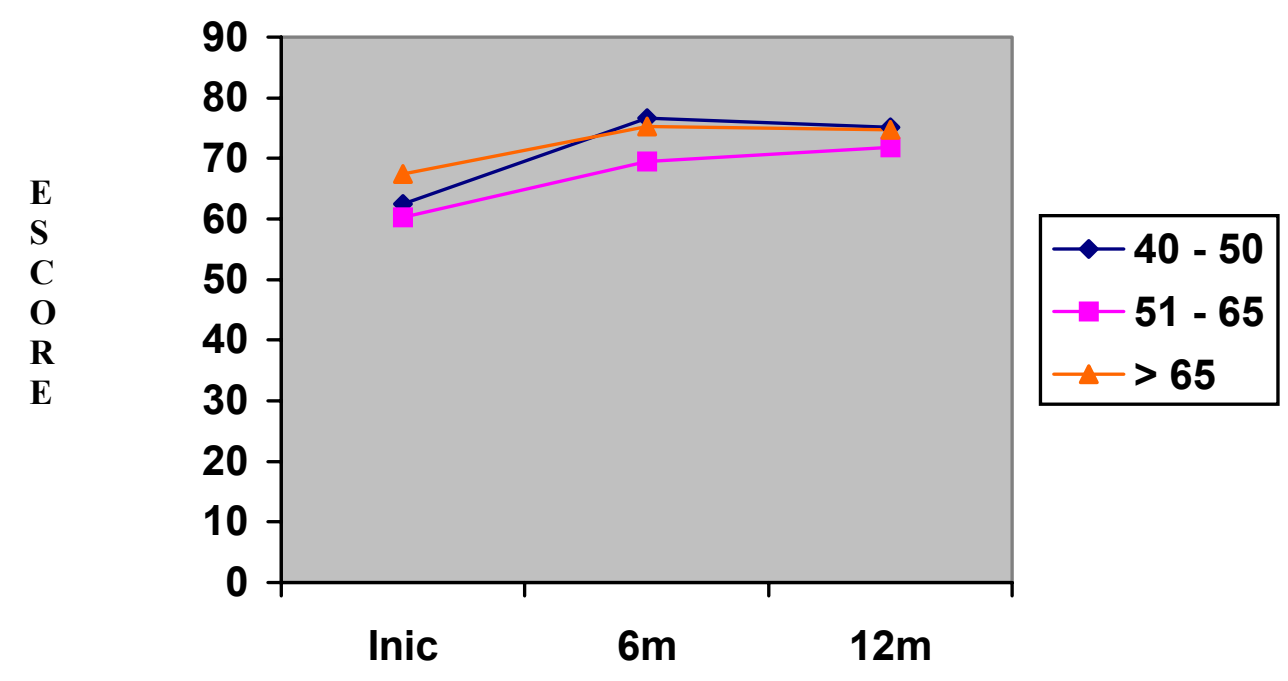

Figura 18 - Distribuição dos resultados de vitalidade (nível de energia e fadiga nas atividades diárias) em mulheres, segundo faixas etárias.

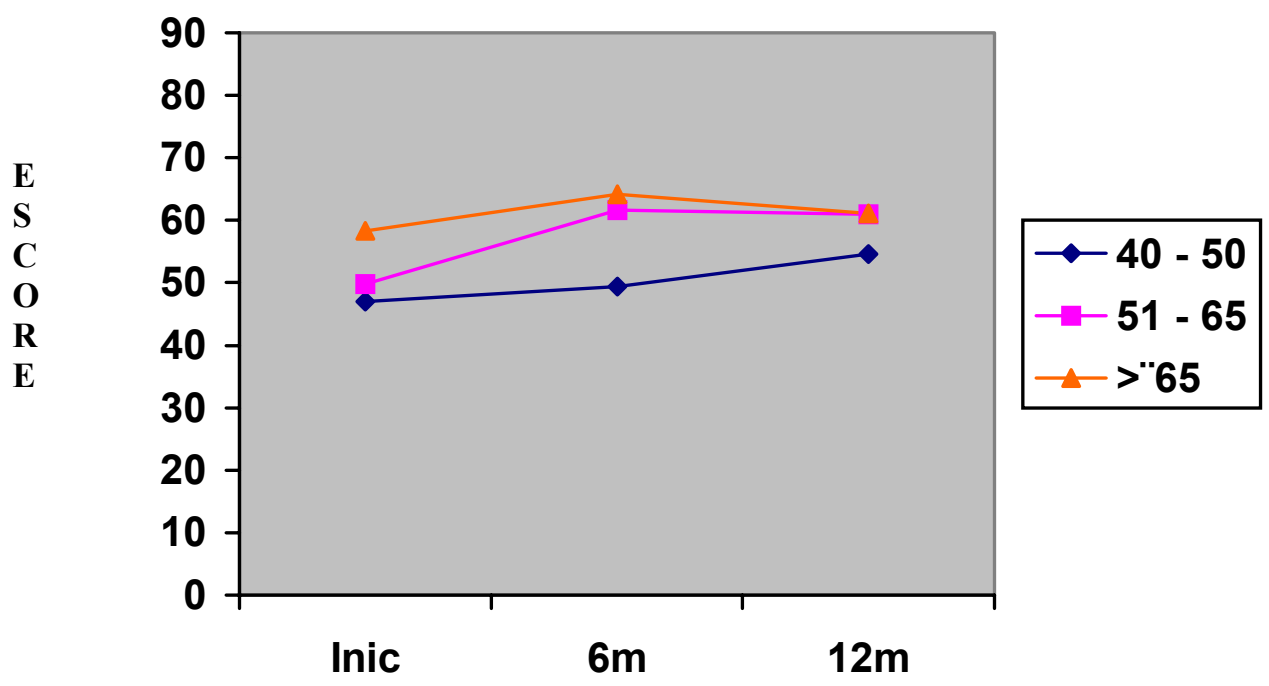


Figura 19 - Distribuição dos resultados dos aspectos sociais (integração em atividades sociais) em homens, segundo faixas etárias.

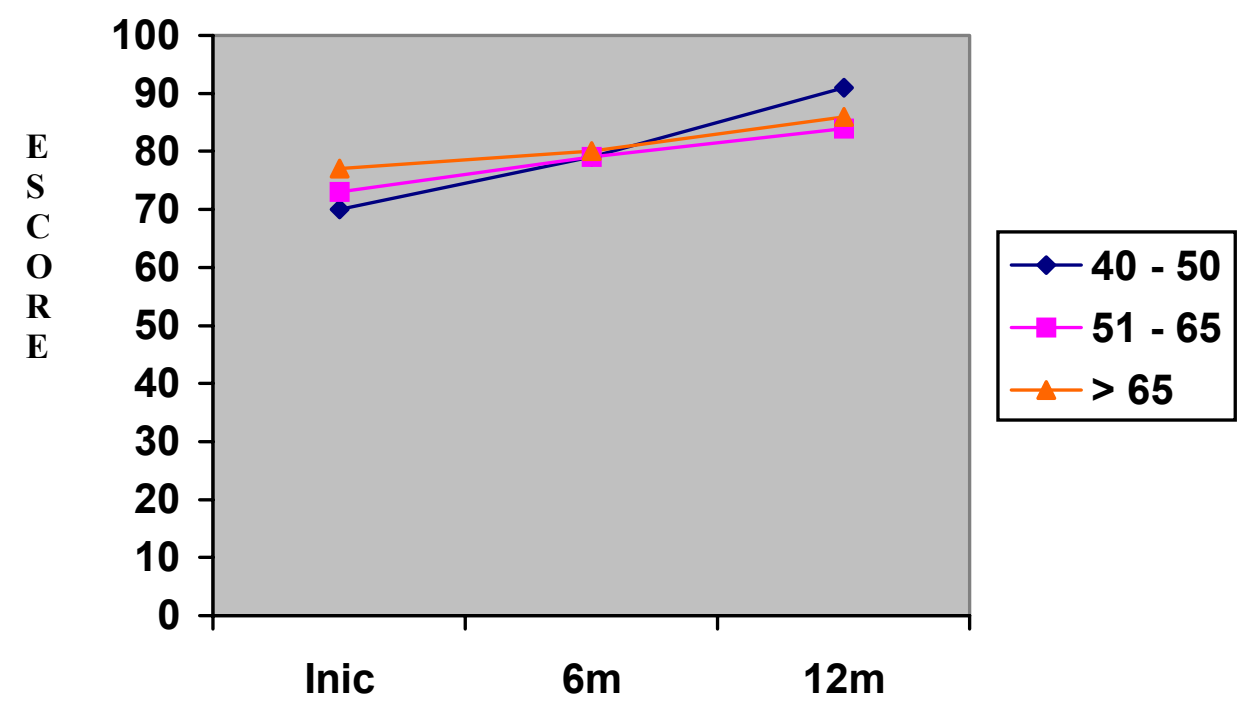

Figura 20 - Distribuição dos resultados dos aspectos sociais (integração em atividades sociais) em mulheres, segundo faixas etárias.

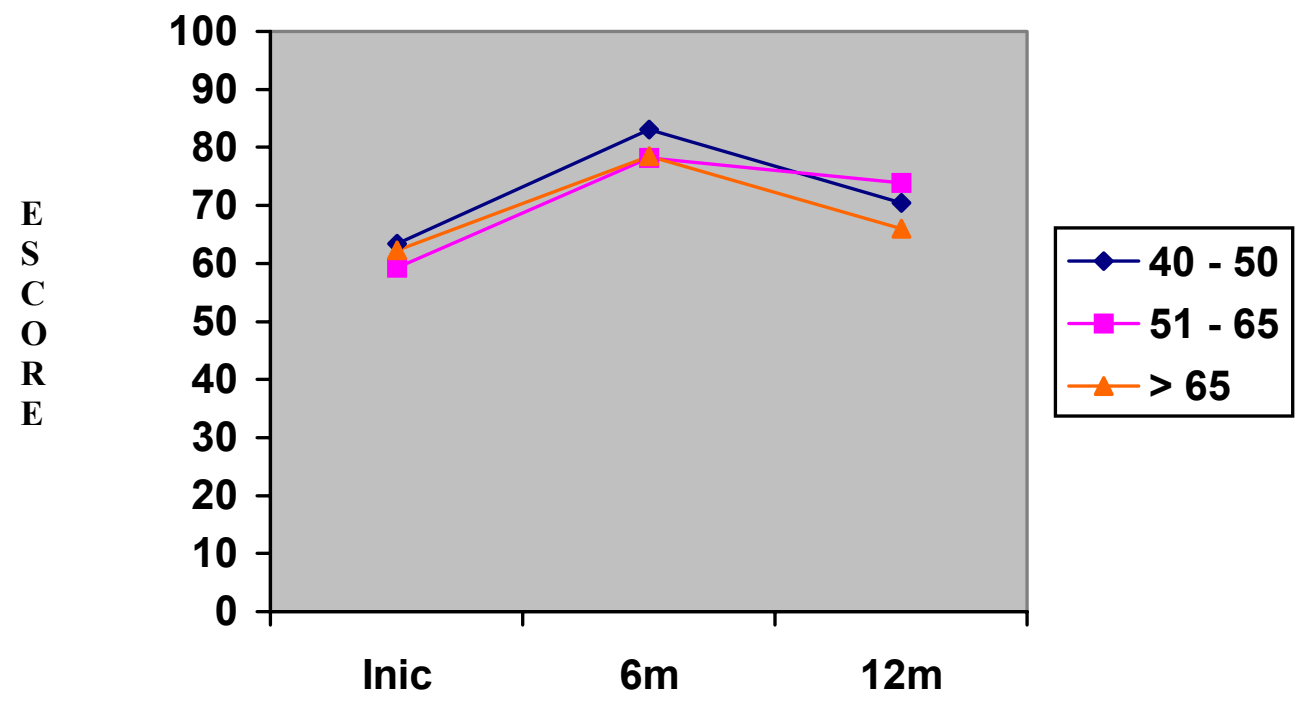


Figura 21 - Distribuição dos resultados do aspecto emocional (dificuldades emocionais que limitam atividades diárias) em homens, segundo faixas etárias.

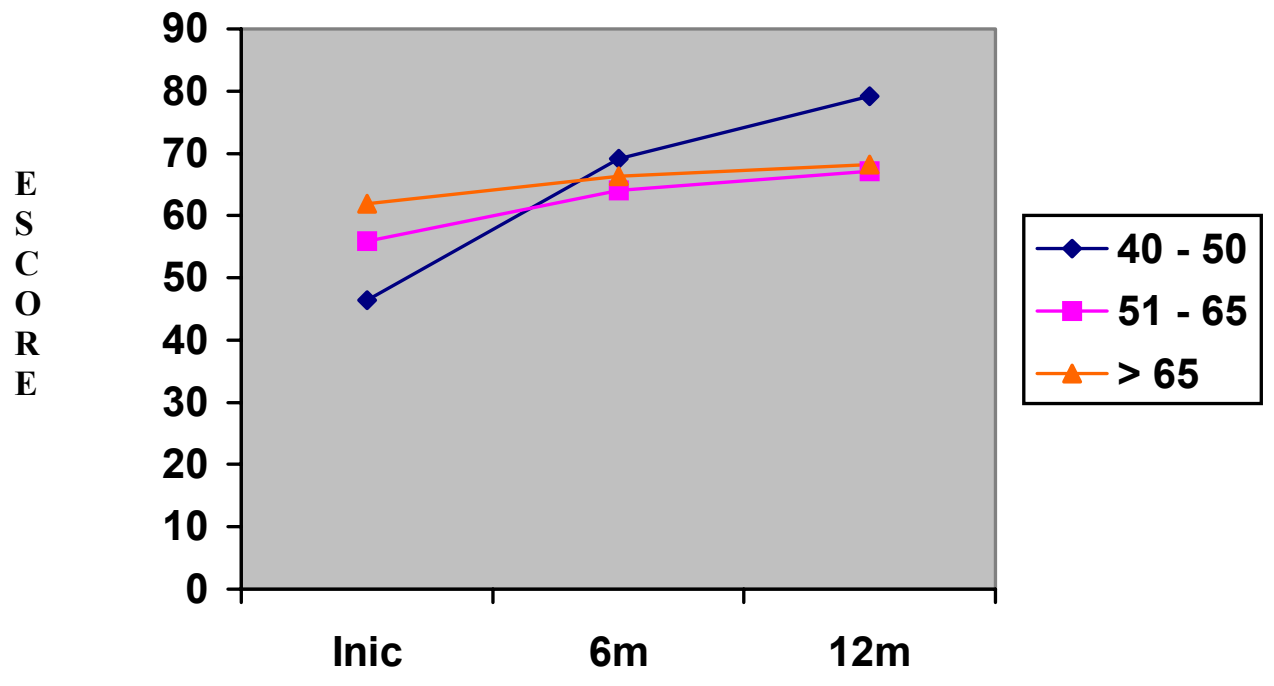

Figura 22 - Distribuição do aspecto emocional (dificuldades emocionais que limitam atividades diárias) em mulheres, segundo faixas etárias.

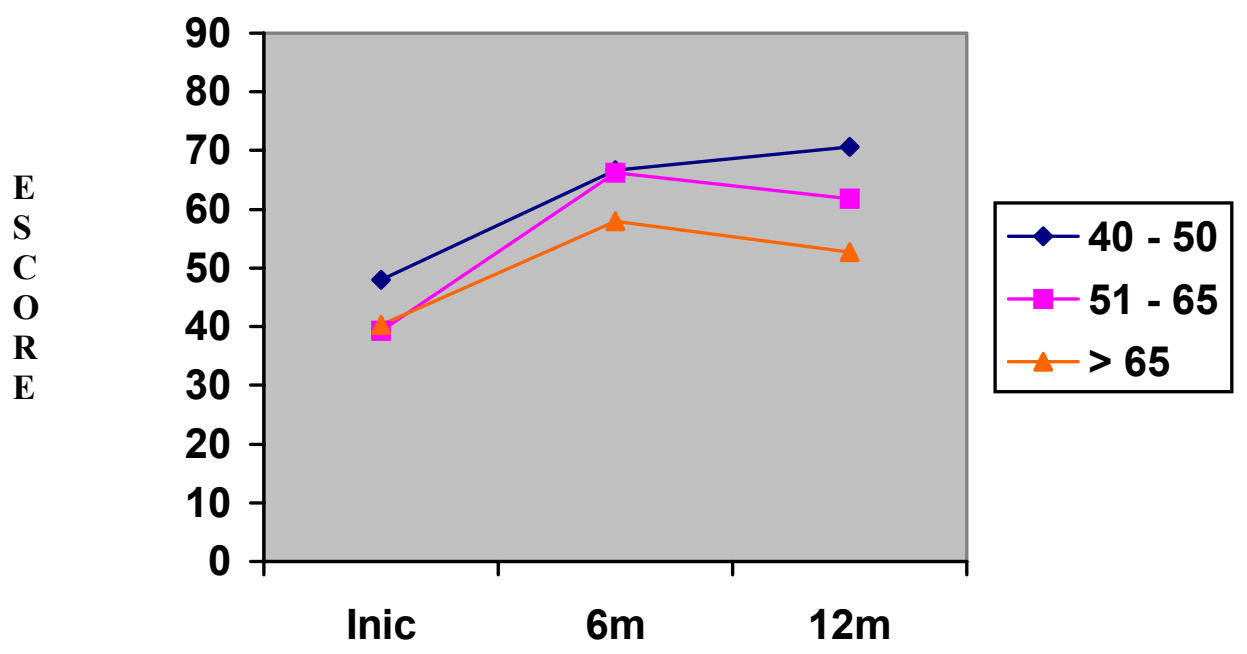


Figura 23 - Distribuição dos resultados de saúde mental (presença de ansiedade, depressão, alterações de comportamento e bem-estar psicológico) em homens, segundo faixas etárias.

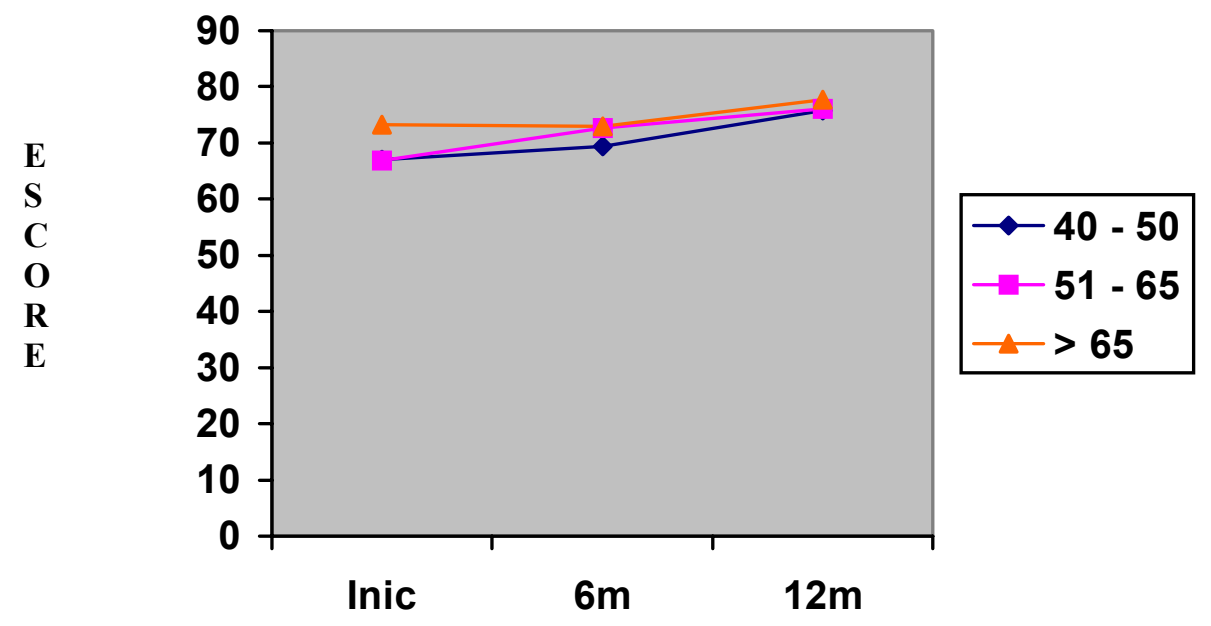

Figura 24 - Distribuição dos resultados de saúde mental em mulheres (presença de ansiedade, depressão, alterações de comportamento e bem-estar psicológico), segundo faixas etárias.

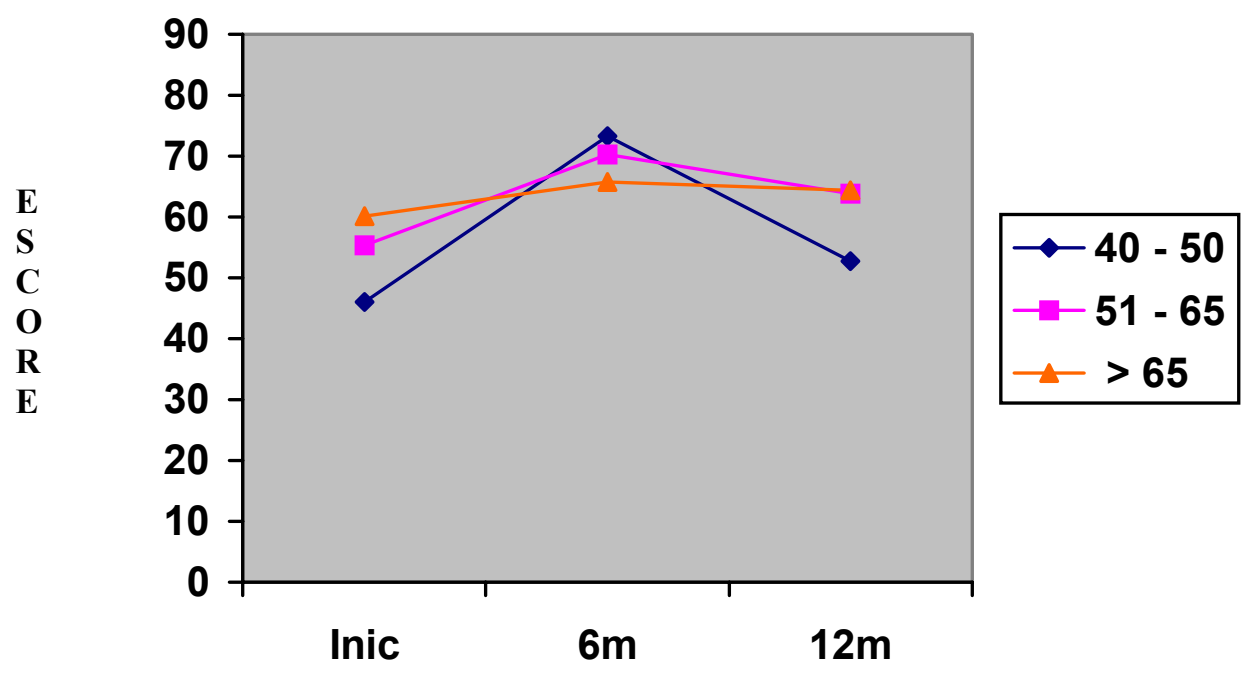




\section{DISCUSSÃO}

O presente estudo avaliou a qualidade de vida por meio da aplicação do questionário genérico SF-36, em pacientes portadores de doença arterial coronária submetidos a uma das três intervenções terapêuticas: tratamento clínico, cirurgia de revascularização do miocárdio ou angioplastia.

Inicialmente serão discutidos os dados do perfil demográfico enfatizando-se a diferenciação entre os gêneros.

Os dados obtidos no questionário de investigação do perfil demográfico permitiram uma visão abrangente das características socioeconômicas e culturais da população estudada, bem como de sua inserção nas atividades profissionais. Ao analisar-se os dados do perfil demográfico com diferenciação entre os gêneros, observa-se que as mulheres eram em média 3,3 anos mais idosas, sendo esta uma diferença significativa. O estudo Framingham demonstra que a incidência da DAC é menor nas mulheres, tanto na pré como após a menopausa, além de existir um intervalo de sete a dez anos de proteção na incidência da DAC nas mulheres (KANNEL et al, 1976). Admite-se que esta diferença decorra do estado hormonal, pois se sabe que a incidência da DAC é menor na prémenopausa, provavelmente devido ao efeito protetor do estrogênio, aumentando significativamente após a menopausa. Os efeitos protetores do estrogênio estão relacionados com melhor perfil lipídico, metabolismo da glicose, menor fibrinogênio sérico e com a ação direta do estrogênio no sistema vascular, inibindo a aterogênese e a trombogênese. Após a menopausa, com a redução das concentrações séricas da HDL-colesterol e aumento da LDL-colesterol, 
instalar-se-ia um perfil lipoprotéico de risco para a DAC (MANSUR e ALDRIGHI, 2000).

No que se refere à escolaridade $69,8 \%$ dos pacientes apresentaram o primeiro grau incompleto e a diferença existente entre os gêneros $(66,7 \%$ dos homens e $77,7 \%$ das mulheres) é significativa.

A taxa de analfabetismo na população acima de 15 anos no Estado de São Paulo no ano de 2000, segundo os dados do Sistema Estadual de Análise de Dados (FUNDAÇÃO SEADE,2004) era de $6,64 \%$, resultado próximo ao da população estudada que foi de $7,4 \%$. A Fundação SEADE aponta também que o número médio de anos de estudo do chefe do domicilio é de 6,43 anos, o que coincide com nossos dados que apontaram para uma porcentagem elevada de pacientes com escolaridade até primeiro grau incompleto $(69,8 \%)$. Nota-se, então, que a escolaridade da população estudada foi coincidente com aquela da população do Estado de São Paulo.

Quanto ao estado civil a diferença significativa entre homens e mulheres em relação ao número de casados e viúvas pode ser explicada pela diferença na esperança de vida que, segundo dados do Ministério da Saúde - DATASUS, é em média seis anos a mais para as mulheres, o que justificaria a porcentagem elevada de viuvez entre elas.

No exercício profissional também encontramos diferenças significativas: $71,1 \%$ das mulheres não exerciam qualquer atividade profissional e apenas $25 \%$ dos homens encontraram-se nessa situação. Vários fatores podem ter contribuído para esse quadro; a idade é um deles. As mulheres eram em média 3,3 anos mais idosas; outro é o fato da aposentadoria feminina ocorrer mais precocemente 
(5 anos antes) e, finalmente, nosso grupo feminino era formado predominantemente por mulheres de baixa escolaridade e como esta condição, na maioria das vezes, redunda no achado de trabalhos mais pesados, é possível que as limitações físicas impostas pela coronariopatia causem restrições ao trabalho fora de casa.

BRUSCHINI (2000) em estudo sobre trabalho feminino chamou a atenção não só para a intensidade da incorporação das mulheres ao mercado, mas também para as características de inclusão, que se dá em dois polos desiguais em relação à qualidade do emprego. De um lado, ocupações de má qualidade quanto a níveis de rendimento, formalização das relações e proteção no trabalho, como o emprego doméstico. No outro extremo, as melhores ocupações, entre as quais estariam as profissões de nível superior, nas quais as mulheres passaram a ingressar principalmente em decorrência da ampliação de sua escolaridade e acesso ao nível superior de ensino, o que não é o caso da população estudada. Estudo de NILES et al (1980) aponta que a depressão é um fator de grande interferência no retorno ao trabalho após as cirurgias de revascularização do miocárdio, ao lado de outras seqüelas psicológicas como ansiedade, distúrbios cognitivos e estresse. Refere ainda que outros fatores também influenciam no retorno ao trabalho como o status de trabalho na fase pré-operatória, os sintomas apresentados após a cirurgia, a idade, o nível educacional, a satisfação prévia com o trabalho e a sensação de bem estar.

Em nosso estudo a avaliação que os pacientes de ambos os sexos fizeram a respeito das dificuldades enfrentadas na execução do trabalho assinalou que com o decorrer do primeiro ano após o procedimento estas diminuíram. Esse fato 
justificar-se-ia pela melhora da capacidade funcional e dos aspectos físicos decorrentes dos procedimentos. Observou-se movimento semelhante no que se refere a necessidades e crises pessoais, bem como com as preocupações financeiras. A coronariopatia exerce fortes impactos físicos, emocionais e sociais comprometendo de forma importante a qualidade de vida, porém após a realização de procedimentos terapêuticos, além da melhora física e emocional, há possibilidade do paciente elaborar a situação vivida e adaptar-se a possíveis limites e alterações no seu estilo de vida.

A análise do perfil demográfico apontou para três achados principais: as mulheres eram mais idosas, possuíam menor escolaridade e houve diferença de gênero em relação ao exercício profissional, sendo os homens mais ativos profissionalmente. A discussão será agora focalizada na avaliação da qualidade de vida comparando-se os resultados obtidos pelos pacientes nas diferentes intervenções terapêuticas.

Nos últimos 20 anos tem havido um reconhecimento crescente da importância da auto-avaliação do paciente em relação a sua qualidade de vida, resultando em aumento de instrumentos para sua mensuração; o SF-36 tem sido um dos mais utilizados em pesquisas de saúde por ser um questionário simples e relativamente breve.

Em termos metodológicos ressalta-se que por ser um instrumento padronizado, elaborado para pesquisar o estado de saúde na prática clínica e em pesquisas populacionais, o SF-36 possibilitou a obtenção de dados objetivos sobre os componentes físicos e mentais. Desta forma, favoreceu a comparação dos três 
grupos de pacientes submetidos às diferentes intervenções terapêuticas, bem como as diferenças entre os gêneros, particularizando-se diversas faixas etárias. Comparando-se a avaliação da qualidade de vida pelo SF-36 dos pacientes submetidos aos três tipos de intervenção terapêutica, pôde-se constatar que as mudanças nos resultados entre a fase inicial, aos seis e aos doze meses foram significativas nas dimensões físicas e mentais. Os aspectos físicos na avaliação inicial eram muito prejudicados pelos sintomas limitantes da coronariopatia como cansaço, dor no peito, dispnéia, que após as intervenções melhoraram, restituindo a possibilidade de uma vida com maior qualidade do ponto de vista físico. Já os aspectos mentais são atingidos inicialmente pelo impacto da perda da saúde. O surgimento da doença aponta para o indivíduo sua vulnerabilidade, fragilidade e traz consigo a consciência da própria finitude. Toda vez que se perde um objeto valorizado, seja a pessoa amada, um objeto material especial, emprego, status, saúde, a resposta imediata é um processo psicológico de luto, que se caracteriza por espírito deprimido, perda de interesse e inibição de atividades. Se este processo tiver um curso normal, chegará a uma fase de elaboração onde o trauma da perda é superado e o estado de saúde é restabelecido (BROMBERG, 1994). Dessa forma, entende-se porque os aspectos mentais do SF-36 mostraram-se inicialmente prejudicados e apresentaram melhora com o passar do tempo.

A comparação da qualidade de vida nos pacientes submetidos aos diferentes tratamentos revelou que os que realizaram cirurgia de revascularização do miocárdio apresentaram os piores resultados na avaliação inicial, porém aos seis e doze meses após o procedimento ocorreu melhora progressiva, superando os 
pacientes submetidos a tratamento clínico e por angioplastia em quase todas as dimensões do SF-36. Por isso, pode-se considerar que embora os pacientes cirúrgicos fossem os mais comprometidos em sua qualidade de vida do ponto de vista dos componentes físicos e mentais, a cirurgia proporcionou incremento significativo de qualidade.

O projeto CABRI (WAHRBORG, 1999) comparou o tratamento cirúrgico com o por angioplastia em pacientes coronariopatas; apesar de não ter usado como instrumento o SF-36 e sim o Nottingham Health Profile seus resultados revelaram que após um ano não ocorrem diferenças significativas na qualidade de vida dos pacientes submetidos a cirurgia de revascularização e angioplastia. Entretanto, seus resultados foram mais favoráveis em relação ao nível de energia no grupo cirúrgico, semelhante ao nosso estudo.

O CABRI também não apontou diferenças entre os dois grupos em termos de mortalidade ou de eventos de infarto do miocárdio não fatal após um ano, mas o número de re-intervenções, consumo de drogas e prevalência de angina após um ano foram menores no grupo cirúrgico.

No presente estudo, os pacientes que realizaram angioplastia apresentaram melhores resultados na fase inicial, porém nas avaliações subseqüentes, embora mostrassem melhora, esta foi de menor intensidade quando comparados aos cirúrgicos. Nos pacientes que receberam tratamento clínico, após a melhora apresentada na avaliação de seis meses, pôde-se observar uma pequena queda nos resultados de um ano.

O estudo RITA-2 (POCOCK et al, 2000) avaliou qualidade de vida pelo SF-36, após três meses, um e três anos em pacientes portadores de angina, submetidos 
a angioplastia e a tratamento clínico. Concluíram que a angioplastia incrementa substancialmente a percepção da qualidade de vida, especialmente em relação à capacidade funcional e vitalidade, quando comparado ao grupo submetido a tratamento clínico, aspecto que também pôde ser constatado em nosso estudo.

No presente estudo ao comparar-se os resultados obtidos por homens e mulheres pôde-se notar diferença significativa entre os gêneros. Os homens portadores de DAC apresentaram melhor qualidade de vida no início do tratamento, com melhores resultados em todas as dimensões do SF-36 quando comparados às mulheres. Além da diferença inicial, observou-se também que os homens se beneficiaram progressivamente seis e doze meses após a realização das intervenções terapêuticas, diferenciando-se das mulheres, que apresentaram melhora após seis meses, porém aos doze tiveram queda nos resultados em todas as dimensões.

$\mathrm{Na}$ avaliação inicial as mulheres demonstraram maior prejuízo em relação aos homens na capacidade funcional, seguida dos aspectos emocionais, aspectos sociais, saúde mental e vitalidade. Dessa forma, o maior prejuízo das mulheres diz respeito aos componentes mentais.

A literatura aponta para a necessidade de uma especial atenção para os transtornos de humor nas mulheres, uma vez que há maior prevalência de depressão na população feminina, quando comparada à masculina, na proporção dois para um. De fato, os distúrbios psiquiátricos mais prevalentes da metade para a última fase da vida são as doenças depressivas, e as mulheres são mais vulneráveis (SCHINDLER, 1987). Tal fato pode ser importante fator de influência na qualidade de vida. A depressão relacionada à cirurgia parece ser 
principalmente um quadro reativo ao estresse provocado pela indicação, pelo trauma cirúrgico e pelas perdas transitórias que a cirurgia acarreta. Em alguns casos a cirurgia mobiliza o estado depressivo em pessoas predispostas ou que já apresentam algum grau de depressão, isto é, já há depressão no pré-operatório, que pode aumentar no pós-operatório imediato e diminuir aos níveis prévios após meses. A depressão é um fator preditivo de reinternação, de pior qualidade de vida, de maior freqüência de sintomas a despeito de melhora objetiva na tolerância ao exercício e de maior número de eventos cardíacos em longo prazo (GLASSMAN e SHAPIRO, 1998).

No presente estudo na avaliação após seis meses, os resultados obtidos pelas mulheres aproximaram-se muito aos dos homens, mantendo-se distante apenas na vitalidade, que é um componente mental, mas que sofre forte influência dos componentes físicos. Aos doze meses, as mulheres voltaram a apresentar prejuízos em relação aos homens, com comprometimento nos componentes físicos e mentais.

Este estudo envolveu pacientes acima de 40 anos; dessa forma as mulheres participantes encontravam-se no climatério pré e após a menopausa. Cabe lembrar que a ocorrência de sintomas no climatério não é universal para todas as mulheres, embora haja queixas e sintomas característicos como ondas de calor, suores frios, ganho de peso, dores de cabeça, entre outros. Segundo BERNSTEIN E LENHART (1993), as queixas de fundo psicológico mais características incluem irritação, variação de humor, depressão, esquecimentos, baixa concentração, excitação, crises de choro, pânico, sensação de sufocamento, preocupações com o corpo, nervosismo e ansiedade. Pode-se 
levantar como hipótese que esses aspectos interferem na auto-avaliação que as mulheres fazem dos diversos aspectos de sua qualidade de vida, justificando-se assim os piores resultados apresentados por elas no SF-36. Além disso, por estarem vivenciando uma fase crítica do desenvolvimento do adulto, a chegada ao meio da vida, talvez estejam mais disponíveis para uma auto-avaliação realística de suas condições físicas gerais e mais atentas para as manifestações de sinais indicadores de limites ou dificuldades.

$\mathrm{Na}$ análise dos resultados por gênero, particularizando-se diferentes faixas etárias, constatou-se que não houve diferença significativa na evolução dos resultados nas diferentes faixas etárias tanto para homens, quanto para mulheres, porém, alguns aspectos merecem ser salientados. Em relação aos aspectos físicos, as mulheres mais jovens (40 a 50 anos) apresentaram um desempenho semelhante ao dos homens, isto é, melhora progressiva com o decorrer do tempo. No estado geral de saúde e na vitalidade, tanto os homens como as mulheres acima de 65 anos apresentaram os melhores resultados na fase inicial. Uma hipótese a ser levantada é que pessoas idosas enfrentam mais facilmente as mudanças decorrentes de perdas, particularmente em relação à diminuição da saúde e talvez utilizem mais eficazmente mecanismos de adaptação a estas perdas, com expectativas mais realistas.

Quanto ao aspecto emocional, homens e mulheres mais jovens apresentaram movimento semelhante de melhora progressiva com o decorrer do tempo. Na fase inicial os homens mais jovens atingiram os piores resultados no aspecto emocional e saúde mental, o que denota que o impacto emocional do adoecer nos homens mais jovens parece ser maior. O surgimento inesperado da doença 
pode ter desencadeado sentimentos de vulnerabilidade e impotência, atingindo-os em seus aspectos mentais; porém com a melhora dos aspectos físicos, podem ter se recuperado emocionalmente atingindo após doze meses da realização dos procedimentos os melhores resultados.

A continuidade deste estudo faz-se necessária a fim de termos uma visão a longo prazo dos rumos que a qualidade de vida desses pacientes irá tomar. Questionamentos surgem. Após cinco anos das intervenções terapêuticas os pacientes cirúrgicos continuarão com melhor qualidade de vida? A diferença entre os gêneros sustentar-se-á?

O projeto MASS II está dando continuidade a avaliação dos pacientes, desta forma no futuro poderemos ter resposta a essas questões.

Por último, cabe ressaltar que o êxito de um tratamento não depende apenas de mudanças físicas objetivas; outros aspectos como relação estabelecida entre o profissional e o paciente, fatores sociais e emocionais interferem na percepção que o paciente tem da evolução de sua doença e tratamento. Os participantes desse estudo tiveram oportunidade de estabelecer uma relação médico-paciente especial e diferenciada da realidade de um hospital escola. Foram sempre atendidos pelo mesmo profissional e avaliados não apenas em relação ao aspecto físico, mas com uma abordagem ampla, envolvendo os diversos segmentos da vida. 


\section{CONCLUSÕES}

- Houve incremento na qualidade de vida dos pacientes submetidos aos três tipos de intervenção terapêutica, entretanto, os pacientes que realizaram cirurgia de revascularização do miocárdio tiveram evolução mais favorável;

- Os homens apresentaram melhor qualidade de vida no início do tratamento e melhora progressiva aos seis e doze meses após as intervenções terapêuticas. Enquanto que as mulheres apresentaram melhora após seis meses seguida de queda aos doze meses;

- Não houve influência significativa das faixas etárias, para ambos os sexos, na evolução da qualidade de vida. 


\section{REFERÊNCIAS}

Abreu MAL. Compreensão holística da síndrome climatérica. Rio de Janeiro; 1992. [Tese de doutorado - Instituto de Psicologia da Universidade Federal do Rio de Janeiro].

Aldrighi JM. Balanço risco/benefício da terapêutica de reposição hormonal: direções para o futuro. Rev Soc Cardiol Estado São Paulo 1996; 734-7.

Anda R, Williamson D, Jones D, Macera C, Eaker E, Glasman A, Marks J. Depressed affect, hopelessness and the risk of ischemic heart disease in a cohort of U.S. adults. Epidemiology 1993; 4: 285 - 94.

Appolinário JC. Terapia hormonal e os sintomas psíquicos na menopausa - Parte 1- Revisão de literatura J Bras Psiquiatr 1992; 44: 169-76.

Barr JT. The outcomes movement and health status measures. J Alied Health 1995; 24: 13-28.

Benedeck T, Rubinstein JR. Studies in psychosomatic medicine, psychosexual functions in women. New York: Ronald; 1952.

Bernstein $A E$, Lenhart $S A$. The psychodynamic treatment of women. Washington: American Psiquiatric Press; 1993. 
Bowling A. What things are important in people's lives ? A survey of the public's judgements to inform scales of health related quality of life. Soc Sci Med 1995; 41: $1447-62$.

Bromberg MHPF. Psicoterapia em situações de perdas e luto. Campinas: Editorial Psy II; 1994.

Bruschini C. Gênero e trabalho no Brasil: novas conquistas ou persistência da discriminação? In: Rocha MIB (org). Trabalho e gênero - mudanças permanências e desafios. Campinas: ABEP; 2000. p 13-58.

Ciconelli RM. Tradução para o português e validação do Questionário Genérico de Avaliação de Qualidade de Vida " Medical Outcomes study 36Item Short-Form Health Survey (SF-36). São Paulo; 1997. [ Tese de doutorado Escola Paulista de Medicina da Universidade Federal de São Paulo].

Cochrane BL. Acute myocardial infarction in women Crit Care Nurs Clin North Am 1992; 4: 279-89.

Dawber T. The Framinghan Study; the epidemiology of atherosclerotic disease. Cambridge: Harvard University Press; 1980.

Deutsch H. Psychology of women. New York: Grune \& Stratton; 1944. 
Dennerstein L, Burrows GD. A review of studies of the psychological symptoms found at the menopause. Maturitas 1978; 1: 55-64.

Favarato MECS. A mulher coronariopata no climatério após a menopausa: implicações na qualidade de vida. São Paulo; 2000. [ Dissertação de MestradoFaculdade de Saúde Pública da Universidade de São Paulo].

Favarato MECS, Aldrighi JM. A mulher coronariopata no climatério após a menopausa: implicações na qualidade de vida. Rev Ass Med Brasil 2001; 47: $339-45$.

Flanagan JC. Measurements of quality of life: current state of art. Arch Phys Med Reabil 1982; 63: 52-62.

Fleck MPA. Avaliação de qualidade de vida. In: Fráguas Jr R, Figueiró JAB. Depressões em medicina interna e em outras condições médicas: depressões secundárias. São Paulo: Atheneu; 2001. p 33- 43.

Fletcher AE. Evaluation of quality of life in clinical trials of cardiovascular disease. J Chron Dis 1987; 40: 557- 66.

Friedman M, Rosenman RH. Association of specific overt behavior pattern with blood and cardiovascular findings: blood cholesterol level, blood clotting time, 
incidence of arcus senilis, and clinical coronary artery disease. JAMA 1959; 169: $1286-96$.

Fundação SEADE. Informações dos municípios paulistas - educação [on line]. Disponível em http://www.seade.gov.br [2004 mar 1].

Glassman AH, Shapiro PA. Depression and course of coronary artery disease. Am J Psychiatry 1998; 155: 4 -11.

Guyatt GH. A taxonomy of health status instruments. J Rheumatol 1995; 22: 1188-90.

Guyatt GH, Naylor D, Juniper E, Heyland DK, Jaeschke R, Cook DJ. User's guides to the medical literature. XII How to use articles about health - related quality of life. JAMA 1997; 277: $1232-6$.

Hamilton GA, Seidman RN. A comparison of the recovery period for women and men after an acute Myocardial infarction Heart Lung 1993; 22: 308 -15.

Haynes SG, Feinleib M, Kannel WB. The relationship of psychosocial factors to coronary heart disease in the Framigham Study III. Eight-year incidence of coronary heart disease. Am J Epidemiol 1980; 111: 37 - 58. 
Holmes T, Rahe R. The social readjustment rating scale. J Psychosom Res $1967 ; 11: 213-8$.

Hopman WA, Towheed T, Anastasiades T, Tenenhouse A, Poliquin S, Berger C. Canadian normative data for the SF-36 health survey CMAJ 2000; 163: 265 71.

Kannel WB, Hjortland MC, McNamara PM, Gordon T. Menopause and risk of cardiovascular disease: The Framingham Study Ann Intern Med 1976; 85: 447 52.

Katz JN, Larson MG, Phillips CB, Fossel AH, Liang MH. Comparative measurement sensitivity of short and longer health status instruments. Med Care 1992; 30: 917-25.

King KB. Psychologic and social aspects of cardiovascular disease. Ann Behav Med 1997; 19: $264-70$.

Lotufo PA. Doenças cardiovasculares no Brasil: por que altas taxas de mortalidade? Rev Soc Cardiol Estado São Paulo 1996: 6: 667 - 71.

Mansur AP, Aldrighi JM. Doença coronária na mulher. Rev Bras Med 2000; 57 : $440-45$. 
Mansur AP, Gomes EPSG, Avakian SD, Favarato D, Cesar LAM, Aldrighi JM, Ramires JAF. Clustering of traditional risk factors and precocity of coronary disease in women. Int J Cardiol 2001; 81: 205 - 209.

Ministério da Saúde. Departamento de Assistência e Promoção à Saúde. Coordenação Materno-Infantil. Assistência ao climatério. Brasília (DF); 1994.

Ministério da Saúde. Datasus. Informações de saúde. [on line]. Disponível em: http://www.datasus.gov.br/ [2004 mar 1].

Murray CVL, Lopez AD et al, editors. The global burden of disease: a comprehensive assessment of mortality and disability from diseases, injuries and risk factors in 1990 and projected to 2020. Cambridge (MA): Harvard University Press; 1996.

Niles NW, Vander Salm TJ, Cutler BS. Return to work after coronary artery bypass operation. J Thorac cardiovasc Surg 1980; 79: 916 - 21.

Papadopoulos C, Beaumont C, Shelley SI. Myocardial infarction and sexual activity of the female patient. Arch Inter Med 1983; 143:1528-30.

Patrick DL, Deyo RA. Generic and disease specific measures in assessing health status and quality of life. Med Care 1989; 27: 217- 32. 
Pocock SJ, Henderson RA, Clayton T, Lyman GH, Chamberlain DA. Quality of life after coronary angioplasty or continued medical tratment for angina: three-year follow-up in the RITA-2 trial. J Am Coll Cardiol 2000; 35: 907 - 14.

Rahe RH, Romo M, Bennett L, Siltanen P. Recent life changes, myocardial infarction and abrupt coronary death. Arch Intern Med 1974; 133: 221 - 8.

Ramos LR. Fatores determinantes do envelhecimento saudável em idosos residentes em centro urbano: Projeto Epidoso, São Paulo. Cad Saúde Pública 2003; 19: $793-8$.

Roeters van Lennep JER, Westerveld HT, Erkelens DW, van der Wall EE. Risk factors for coronary heart disease: implications of gender. Cardiovasc Research 2002; 53: $538-49$.

Romano BW. Qualidade de vida: teoria e prática. Rev Soc Cardiol Estado São Paulo 1993; 3 (6 supl A): 6 - 9.

Rozanski A, Blumenthal JA, Kaplan J. Impact of psychological factors on the pathogenesis of cardiovascular disease and implications for therapy. Circulation 1999; 99: $2192-217$.

Schindler BA. The psychiatric disorders of midlife Med Clin North Am 1987; 71: $71-85$. 
Schleifer SJ, Macari-Hinson MM, Coyle DA. The nature and course of depression following myocardial infarction. Arch Intern Med 1989; 149: 1785 - 9.

Skultans V. The simbolic significance of menstruation and menopause. In: Willians $\mathrm{JH}$, organizer. Psychology of women: selected readings. New York: WW Norton \& Company; 1979. p $115-127$.

The WHOQOL Group. The World Health Organization quality of life assesment (WHOQOL): development and general psychometric properties. Soc Sci Med 1998; 46: $1569-85$.

Thonet C. Climacteric: una perspectiva psicosomatica Rev Med Chile 1985; 113 : 1222-6.

Wahrborg P. Quality of life after coronary angioplasty or bypass surgery. 1-year follow-up in the Coronary Angioplasty versus Bypass Revascularization investigation (CABRI) trial. Eur Heart J 1999; 20: 653 - 8.

Ware JE. Standards for validating health measures: definition and content $\mathbf{J}$ Chron Dis 1987; 40: 473-80.

Ware JE, Sherbourne CD. The MOS 36-item short-form health survey (SF-36). I. Conceptual frame work and item selection. Med Care 1992; 30: 473 - 83. 
Wenger NK. Coronary disease in women. Annu Rev Med 1985; 36: 285 - 94.

Wenger NK. Epidemiology of coronary heart disease in women. Rev Soc Cardiol Estado São Paulo 1996; 6: 672 - 80. 